Palacios, Juan Carlos. La reforma de la economía cubana. Evaluación de su potencial impacto en el crecimiento económico. http://dx.doi.org/10.5209/rev_PADE.2012.n24.39545

\title{
LA REFORMA DE LA ECONOMÍA CUBANA. EVALUACIÓN DE SU POTENCIAL IMPACTO EN EL CRECIMIENTO ECONÓMICO
}

\section{THE REFORM OF THE CUBAN ECONOMY. EVALUATION OF ITS POTENTIAL IMPACT ON THE ECONOMIC GROWTH}

\author{
Juan Carlos Palacios Cívico \\ Departamento de Política Económica y Estructura Económica Mundial \\ Universidad de Barcelona \\ jpalacioscivico@yahoo.es \\ Fecha recepción: 24 de octubre de 2011 \\ Fecha aceptación: 9 de abril de 2012
}

\begin{abstract}
RESUMEN
El presente artículo analiza el alcance de las transformaciones propuestas en el VI Congreso del Partido Comunista de Cuba (PCC), la forma en que éstas pueden contribuir al crecimiento económico y a la superación de las principales restricciones de la economía cubana, así como aquellos aspectos que, a juicio del autor, permitirían estimular la eficiencia del modelo, pero que no han sido incluidos en la agenda del Congreso. Dicho análisis parte de la hipótesis de que el crecimiento económico cubano se encuentra restringido por la escasez de divisas y por un marco regulatorio excesivamente centralizado, fundamentada en los trabajos teóricos y empíricos que han abordado el tema del crecimiento, la revisión de la bibliografía que analiza la economía cubana durante las últimas décadas y el trabajo de campo llevado a cabo por el autor entre septiembre del 2010 y mayo del 2011.
\end{abstract}

Palabras ClAVe: reformas económicas, socialismo cubano, eficiencia, crecimiento económico.

JEL: P2, N16, E2.

\begin{abstract}
This paper analyzes the deep transformations purposed in the VI Cuban Communist Party Congress, the way they will contribute to the economic growth, the solution of the main restrictions of the Cuban economy, and those outstanding points which have not been included in the political agenda. The analysis starts from the hypothesis that Cuban economic growth is restricted by the lack of foreign currency and a very centralized regulatory framework, based on the theoretical and empirical surveys about economic growth, bibliographic analysis about the Cuban economy over the last decades and the fieldwork carried out by author from September 2010 to May 2011.
\end{abstract}

KEY WORDS: economic reforms, Cuban socialism, efficiency, economic growth. 
Palacios, Juan Carlos. La reforma de la economía cubana. Evaluación de su potencial impacto en el crecimiento económico.

\section{INTRODUCCIÓN}

El aplazamiento del VI congreso de PCC, anunciado en un primer momento para la segunda mitad del 2009, hacía prever la magnitud de los cambios que iban a promoverse en dicho congreso. La publicación del proyecto de lineamientos el 1 de noviembre de $2010^{1}$, confirmó el impulso transformador que el VI congreso del PCC iba a imprimir al desarrollo del socialismo cubano. Entre los cambios de mayor trascendencia incluidos en la resolución aprobada, se encuentran el desarrollo por primera vez de una ley de quiebra empresarial, la renuncia al pleno empleo como objetivo prioritario, la autorización del trabajo asalariado fuera de la esfera estatal, la extensión de las cooperativas a los sectores industrial y de servicios o el recuperado protagonismo de la autonomía empresarial y de los mecanismos de mercado, sin renunciar con ello al carácter socialista del modelo económico ni a las conquistas sociales que lo definen.

Hasta el momento solo se conocen los objetivos que definen la estrategia económica de los próximos años. El hecho de que no se haya concretado aún el modo en que éstos serán implementados puede elevar la incertidumbre en cuanto al cumplimiento o no de las metas marcadas; máxime cuando algunas de las medidas fueron ya aplicadas y revertidas en el pasado. En esta ocasión sin embargo, existen señales que apuntan hacia un mayor compromiso con el cumplimiento de dichos objetivos y con la irreversibilidad de los mismos. Entre ellas, pueden citarse la voluntad expresa que ha habido desde un primer momento, para que el pueblo cubano participe de forma activa en el proceso de reformas $^{2}$, un discurso oficial claro y repetido sobre la trascendencia del proceso y sobre la irreversibilidad del mismo ${ }^{3}$ o movimientos políticos como el nombramiento del ministro de economía, para dedicarse plenamente al proceso de implementación. Todo ello ha contribuido a la generación de unas expectativas que el gobierno cubano tendrá que saber gestionar en los próximos años.

Más allá de las dudas sobre las posibilidades de cumplir con la reforma del marco regulatorio aprobada en los lineamientos, el objetivo principal del presente trabajo se centra en contribuir al debate sobre el alcance y efectos de la misma. Con ese fin se persigue identificar en la nueva estrategia, aquellos cambios regulatorios que pudieron expandir en el pasado los niveles de eficiencia de la economía, así como los principales obstáculos, aún vigentes, para el cumplimiento de dicho objetivo.

El análisis de los lineamientos planteado, parte de la premisa de que el crecimiento económico cubano se encuentra restringido simultáneamente por factores de oferta (un marco regulatorio excesivamente centralizado) y de demanda (la disponibilidad de divisas). Una premisa que es evaluada en el punto tres del trabajo, mediante el análisis bibliográfico de la economía cubana, el examen de los principales indicadores macroeconómicos del país durante el

\footnotetext{
${ }_{1}^{1}$ Disponible en http://www.prensa-latina.cu/Dossiers/ProyectoLineamientosPCC.pdf

${ }^{2}$ Los lineamientos han sido discutidos desde su publicación en noviembre del 2010 y durante cinco meses en todos los centros de trabajo y barrios del país.

${ }^{3}$ Raúl Castro se refería públicamente al actual proceso de cambios como "nuestra última oportunidad para cambiar las cosas" (Leal, 2011).
} 
Palacios, Juan Carlos. La reforma de la economía cubana. Evaluación de su potencial impacto en el crecimiento económico.

periodo de estudio y numerosas entrevistas a profesores, investigadores y expertos cubanos, enmarcadas en la estancia de investigación realizada en colaboración con la Universidad de la Habana, el Centro de Estudios de Economía Cubana y el Instituto Nacional de Investigaciones Económicas, durante los meses de septiembre del 2010 y mayo del $2011^{4}$.

En lo que se refiere a la metodología, si bien pueden encontrarse trabajos que han estudiado los determinantes del crecimiento de la economía cubana desde un enfoque eminentemente econométrico (éstos se incluyen en la revisión bibliográfica descrita en el punto dos) es importante señalar que las dificultades para construir series estadísticas confiables, completas y homogéneas, relativas a la economía cubana, obligan a considerar con cautela las conclusiones que puedan derivarse de cualquier análisis econométrico aplicado al caso cubano ${ }^{5}$.

La estructura del artículo es la siguiente: en el punto dos se revisa la bibliografía sobre crecimiento económico. En él se resumen los principales trabajos que han abordado el tema, tanto desde un punto de vista teórico como empírico, poniendo especial énfasis en los estudios aplicados para el caso cubano. El punto tres se dedica a examinar la importancia que tanto el sector externo como el marco regulatorio han tenido en la explicación del PIB cubano durante las últimas décadas. En el punto cuatro, se analizan las principales reformas regulatorias propuestas en el VI Congreso del PCC; diferenciando, a partir del análisis planteado previamente, entre aquellos elementos que pueden favorecer la expansión de la productividad y la renta de la economía cubana y los que por el contrario, pueden continuar inhibiendo la expansión de ambas variables en el futuro.

\section{MARCo TEÓRICO Y PRINCIPALES REFERENCIAS BIBLIOGRÁFICAS}

La identificación de los determinantes del crecimiento económico y de las diferencias de renta entre países, ha sido uno de los temas más recurrentes en la literatura económica desde los orígenes de la economía como ciencia. Autores clásicos como Adam Smith, Thomas Malthus, John Stuart Mil, David Ricardo o Karl Marx plasmaron ya en sus trabajos la preocupación por el crecimiento de la economía.

A partir de los resultados sobre el equilibrio estático de John Maynard Keynes, los economistas Roy Harrod y D.Domar extendieron al largo plazo el análisis sobre la inestabilidad del capitalismo. Su trabajo serviría de inspiración a estudios posteriores que centraron su análisis en el crecimiento equilibrado con

\footnotetext{
${ }^{4}$ Aprovecho para mostrar mi agradecimiento a todos los profesores e investigadores del Instituto Nacional de Investigaciones Económicas, el Centro de Estudios de la Economía Cubana y la Facultad de Economía de la Universidad de la Habana, con los que tuve el placer de mantener un encuentro académico durante mi visita.

${ }^{5}$ Entre los principales problemas que presentan las estadísticas cubanas destacan: la dificultad de acceder a series largas y homogéneas, los cambios de criterio en las agregaciones sectoriales o el cambio de la metodología utilizada desde 2004 en la valoración del PIB. Adicionalmente, en el uso de indicadores de inputs y outputs, debe considerarse el problema que representa la distorsión de los precios en base a los que se calculan o la segmentación de los mercados en donde se comercializan.
} 
Palacios, Juan Carlos. La reforma de la economía cubana. Evaluación de su potencial impacto en el crecimiento económico.

pleno empleo y que han sido agrupados dentro de la teoría del Crecimiento Exógeno.

Por su parte, autores como Solow, Swan, Meade o Tobin, representantes de la escuela neoclásica, recuperaban en sus modelos la teoría de la productividad marginal y la sustituibilidad entre los factores de producción. A diferencia de los economistas postkeynesianos centrados en los factores de demanda, los modelos neoclásicos centraron su explicación del crecimiento en factores de oferta, como el progreso técnico y la disponibilidad de factores de producción. Los tres supuestos básicos en los que fundamentaron sus modelos fueron: el crecimiento constante y exógeno de la fueza de trabajo y del progreso técnico, la asimilación del ahorro con la inversión y los rendimientos constantes de la función de producción y decrecientes para cada uno de los factores individualmente.

Un mundo regido por tales supuestos debería tender hacia la convergencia en los niveles de renta de los países, consecuencia de la mayor productividad del capital en los países subdesarrollados con un menor acerbo de capital. Sin embargo, las crecientes divergencias en renta per cápita ponían de relieve las dificultades de los modelos neoclásicos para explicar la realidad y motivó la aparición de nuevas corrientes de pensamiento.

La necesidad de recuperar el contexto histórico y cultural de los países fue desde la década de los 70 una de las reivindicaciones principales de la Nueva Economía Institucional. Con un análisis más interdisciplinario y menos basado en modelos matemáticos, autores como Ronald Coase, Douglass North u Oliver Williamson otorgaban a las instituciones un papel central en la explicación del comportamiento económico.

A mediados de la siguiente década, comenzaron a aparecer trabajos que retomaron los modelos neoclásicos y reformularon algunos de sus supuestos básicos, como la exogeneidad de los factores de producción y del progreso técnico o los rendimientos constantes a escala de la función de producción. Con ello, empezaba a conformarse un nuevo enfoque sobre la cuestión, representado por los modelos de crecimiento endógeno. Éstos incluían en el análisis nuevos determinantes de la renta como el capital humano ${ }^{6}$, el gasto en Investigación y Desarrollo $(\mathrm{I}+\mathrm{D})^{7}$ o el capital público en infraestructura ${ }^{8}$. La inclusión de los nuevos factores justificaba la aparición de externalidades positivas que posibilitaban la existencia de rendimientos crecientes a escala, necesaria para explicar el crecimiento a largo plazo de las economías.

\footnotetext{
${ }^{6}$ Ya en la década de los 60 pueden encontrarse trabajos que demuestran los rendimientos sociales de la educación (Shultz, 1961 o Arrow ,1962). En 1982, Lucas contrastó el efecto positivo del capital humano en el crecimiento económico. En su trabajo descompone dicho capital en la acumulación de conocimientos (schooling) por un lado y la acumulación involuntaria (learning by doing) por otro.

7 La correlación positiva entre los gastos de I+D y el capital humano con los niveles de productividad es contrastada en Griliches (1958 y 1979).

${ }^{8}$ Barro (1990) encuentra evidencia del efecto positivo de las infraestructuras con el crecimiento al facilitar la circulación de informaciones, bienes y personas.
} 
Palacios, Juan Carlos. La reforma de la economía cubana. Evaluación de su potencial impacto en el crecimiento económico.

Algunos economistas fueron sin embargo más lejos en su crítica a los modelos neoclásicos al no cuestionar únicamente el supuesto de rendimientos decrecientes de los factores de producción, sino el propio carácter exógeno de los mismos. Los trabajos de Kaldor o Thirlwall iniciaron en los 70 una nueva línea de pensamiento, al basar sus modelos en la expansión de la demanda y más concretamente, por ser el único componente autónomo de ésta, en las exportaciones. Thirlwall (1979) parte del multiplicador del comercio exterior de Kaldor para acabar concluyendo que en el largo plazo las tasas de crecimiento de las economías se encuentran restringidas por la disponibilidad de divisas, determinadas a su vez por las exportaciones, los términos de intercambio y la elasticidad renta de la demanda de importaciones. Tres años más tarde, añadiría en su trabajo con Hussein el financiamiento externo como determinante de la tasa de crecimiento restringida por la Balanza de Pagos.

En el contexto cubano cabe señalar que durante décadas el crecimiento económico no ha sido tratado por los autores e investigadores del país como un tema prioritario. En su lugar, la preocupación por el desarrollo económico y social ocupó un espacio central en la agenda política y académica. En la década de los 80 comienza a apreciarse sin embargo una mayor preocupación por los temas relacionados con la eficiencia y el crecimiento, recogida en trabajos como Castañeda (1982) y Figueroa et al. (1983). El primer análisis basado en funciones de producción Cobb-Douglas se encuentra en González, Martínez et al (1989). Años más tarde, Madrid-Aris (1997) y Mendoza y Álvarez (2002) utilizarían el mismo enfoque para, mediante un ejercicio de contabilidad de crecimiento, estimar las contribuciones de los factores productivos. Ambos estudios señalan a la Productividad Total de los Factores (PTF) ${ }^{9}$ como el factor determinante de la recuperación de los 90.

Mendoza (2003) amplía la función de producción neoclásica, al añadir en la especificación del modelo, el capital humano como factor explicativo del crecimiento económico cubano. En él, contrariamente a lo concluido en la literatura, detecta una relación negativa entre éste y la productividad global de la economía. El cambio estructural y su relevancia en el crecimiento económico, también ha sido objeto de análisis en otros estudios como Rodríguez (1985), Rodríguez (1990), Figueras (1999) y Torres (2007).

Sin embargo, hasta 2007 no encontramos ningún trabajo que analice los factores que permitieron la recuperación de la eficiencia de la economía, señalada en la mayoría de los estudios como el factor determinante de la recuperación de los 90 (ver Cuadro 2). Ese año, Doimeadios (2007) contrasta por vez primera el efecto positivo de un grupo de variables (proxys de cambio estructural, apertura externa y marco regulatorio) en el crecimiento de la PTF cubana.

\footnotetext{
9 A partir de una función de producción de tipo Cobb-Douglas con rendimientos constantes a escala y ausencia de ineficiencia técnica, Solow (1957) encuentra que la mayor parte del PIB no se explica por la expansión de los factores productivos tradicionales (capital y trabajo) sino por un conjunto de factores desconocidos recogidos en lo que desde entonces pasó a conocerse como el residuo de Solow o Productividad Total de los Factores.
} 
Palacios, Juan Carlos. La reforma de la economía cubana. Evaluación de su potencial impacto en el crecimiento económico.

\section{MARCO REGULATORIO, DISPONIBILIDAD DE DIVISAS Y RESTRICCIONES ESTRUCTURALES AL CRECIMIENTO ECONÓMICO}

El nuevo rumbo trazado en el VI Congreso del PCC marca un destino prioritario y recurrente en la historia de la economía cubana de las últimas décadas: la mejora de la eficiencia global de la economía. Con ese fin, vuelve a marcarse el camino de la descentralización y liberalización de determinados ámbitos del funcionamiento económico, aceptando con ello la correlación entre descentralización económica y el nivel de renta, analizada en el punto 3.2 del presente trabajo.

Una segunda cuestión que merece igualmente ser objeto de análisis, es el hecho de que la crítica situación que atraviesa el país en la actualidad vuelve a estar precedida por una crisis de divisas derivada de la contracción de las exportaciones. En ese sentido, la restricción externa a la que Thirlwall se refiere en sus Modelos de Crecimiento Restringido por la Balanza de Pagos, parecería verse confirmada por la propia realidad económica cubana de las últimas décadas.

\subsection{El equilibrio de la Balanza de Pagos como restricción de demanda del crecimiento económico cubano ${ }^{10}$}

La consideración del equilibrio de la Balanza de Pagos como una restricción al crecimiento económico parece una hipótesis plausible para el caso de una economía abierta y subdesarrollada como la cubana, con un sector productivo fuertemente dependiente de las importaciones de insumos y de tecnología ${ }^{11}$.

Los trabajos empíricos que han abordado el tema para el caso de la economía cubana han validado dicha hipótesis para el largo y el corto plazo. En el Cuadro 1 se incluye la estimación de la elasticidad ingreso de la demanda de las importaciones $(\eta)$, así como el periodo de referencia de los principales trabajos.

CuAdro 1. Modelo CRBP APLICADO A Cuba

\begin{tabular}{lcc}
\hline \multicolumn{1}{c}{ Artículo } & Periodo & $\eta$ \\
\hline Mendoza (2000) & $1973-1999$ & 1,75 \\
Cribeiro y Triana (2005) & $1960-2004$ & 1,87 \\
Vidal y Fundora (2008) & $1950-2005$ & 2,08 \\
Fugarolas y Mañalich (2009) & $1950-2005$ & 1,77 \\
\hline Fuente: elaboración propia a partir de la bibliografía referenciada.
\end{tabular}

\footnotetext{
${ }^{10}$ La esencia de la ley marxista de reproducción ampliada ya asumía la restricción que la demanda supone al crecimiento económico en el sistema capitalista. Más tarde, Stalin reinterpretaría dicha ley, al afirmar que a diferencia del capitalismo, el socialismo no se veía limitado por la demanda, puesto que el objetivo último del sistema era el de satisfacer las necesidades del pueblo y éstas eran siempre crecientes en el tiempo (Lavigne, 1995).

${ }_{11}$ Durante el periodo $2003-2008$ cerca del $70 \%$ de los bienes de equipo del país fueron importados (ONE, varios años).
} 
Palacios, Juan Carlos. La reforma de la economía cubana. Evaluación de su potencial impacto en el crecimiento económico.

De los resultados incluidos en el Cuadro 1 puede inferirse que el crecimiento de un $1 \%$ del producto ha requerido en el caso cubano de un crecimiento de las exportaciones cercano al $2 \%$.

La escasez reservas de divisas y las dificultades a las que ha tenido que hacer frente el país para acceder a financiación internacional durante las últimas décadas, pueden estar justificando la mayor sensibilidad que las importaciones cubanas presentan respecto del comportamiento de sus exportaciones, al ser ésta su principal fuente de financiación. El Gráfico 1 muestra la evolucion paralela que ambas series han mantenido durante el periodo 1975-2009; así como la aparente correlacion de éstas con la evolucion del PIB del país, lo que sin duda refuerza la hipótesis de que el equilibrio en Balanza de Pagos puede estar restringiendo el crecimiento económico cubano.

\section{GRÁFICO 1. PIB, EXPORTACIONES E IMPORTACIONES DE BIENES Y SERVICIOS DE CUBA ENTRE 1975 Y 2009ª}

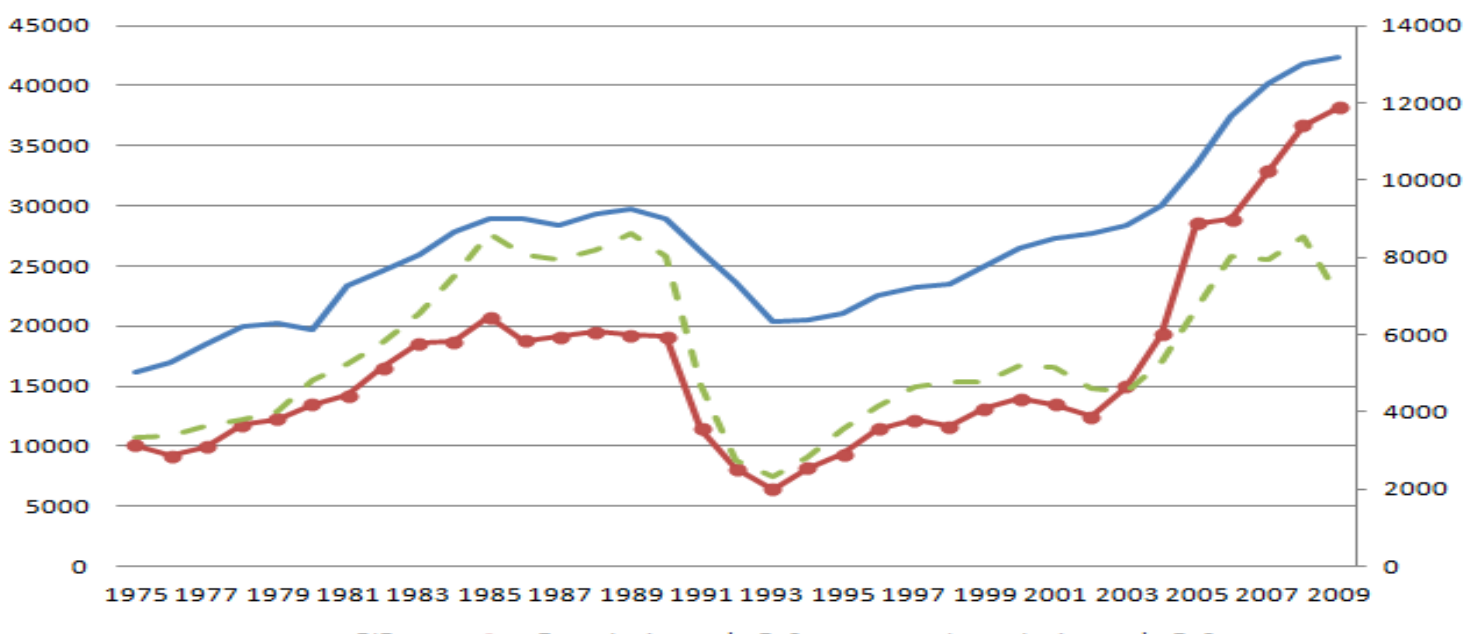

Fuente: elaboración propia a partir de datos de la Oficina Nacional de Estadística (ONE) y del Instituto Nacional de Investigaciones Económicas (INIE).

${ }^{a}$ PIB en precios constantes de 1997 y exportaciones e importaciones en precios corrientes.

En 1972, con la formalización del ingreso en el Consejo de Ayuda Mutua Económica (CAME), Cuba aseguraba el acceso de sus productos a mercados garantizados y con precios subvencionados ${ }^{12}$. Productos como el azúcar, el níquel, el tabaco o la pesca eran vendidos al área socialista a precios superiores a los pagados en el mercado mundial. Paralelamente, las importaciones crecieron de forma sostenida hasta 1985, permitiendo la adaptación de la industria nacional a los patrones productivos y de consumo de los países del bloque soviético. Como resultado, el periodo comprendido entre 1975 y 1985 se caracterizó por un gran dinamismo tanto en los flujos de comercio exterior como en el producto de la economía, al crecer durante dicho periodo a tasas anuales superiores al $5 \%$.

Sin embargo, durante la segunda mitad de los ochenta los flujos de comercio exterior se estancaron y el crecimiento de la economía fue prácticamente nulo, al crecer este último a una tasa promedia del $0,5 \%$. Entre las principales

${ }^{12}$ Los términos de intercambio mejoraron en un 90\% entre 1973 y 1975 (ONE, varios años). 
Palacios, Juan Carlos. La reforma de la economía cubana. Evaluación de su potencial impacto en el crecimiento económico.

razones que explican dicho estancamiento se encuentran el propio agotamiento del modelo de desarrollo extensivo ${ }^{13}$ (tal y como muestra el deterioro de la productividad del capital del Gráfico 2) y el ajuste de los favorables términos de intercambio con los países del área socialista. "Los resultados de la coordinación de planes entre 1986 y 1990 mostraron una desaceleración de los volúmenes de recursos y de las condiciones del intercambio" (Álvarez, 1995: 5), que acabaría concretándose en una contracción de más del 50\% de las exportaciones de petróleo y del $27 \%$ de las exportaciones en divisas (ONE, varios años). Como consecuencia, en 1986 Cuba anunció la moratoria en el pago de sus obligaciones en divisas. La falta de acuerdo con los acreedores extranjeros suponía la expulsión de facto del país caribeño de los circuitos internacionales de crédito, complicando aún más las posibilidades de financiar el crecimiento de su economía.

Con la desintegración del bloque socialista en 1990, Cuba perdía a su socio comercial más importante, al representar en ese momento cerca del $85 \%$ de sus intercambios comerciales (ONE, varios años). El restablecimiento de las relaciones comerciales internacionales requerió de cambios profundos tanto en el marco regulatorio como en la política industrial del país. Entre las medidas mas relevantes estuvieron la descentralización del comercio exterior, la autorización de la Inversión Extranjera Directa en sectores clave, la legalización del dólar y una política activa de sustitución de importaciones y de fomento exportador.

El escaso margen para buscar financiación internacional, concedió un carácter prioritario al programa de desarrollo exportador. Los ejes sobre los que se articuló dicho programa fueron el desarrollo de políticas sectoriales dirigidas a estimular las actividades generadoras de ingresos en divisas, la modificaciones del marco institucional vigente, la firma de nuevos acuerdos para la reorientación de los mercados, las mejoras cualitativas en la gestión de las empresas vinculadas al sector exterior, el establecimiento de regímenes aduaneros especiales y de concesiones arancelarias recíprocas o la aprobación de un Programa Nacional de Incentivos para el Fomento de Exportaciones (Marquetti, 2006).

Las reformas cumplieron con el propósito de reactivar y diversificar las exportaciones cubanas ${ }^{14}$ y recuperar la capacidad importadora del país, vital para completar la canasta básica de consumo de la población y el abastecimiento de los sectores que lideraron la recuperación de la economía en los 90. El crecimiento de las importaciones se mantuvo estable hasta 2006, año en que los pagos realizados por el país en concepto de devolución de deuda, obligaron a reducir el volumen de sus importaciones ${ }^{15}$.

\footnotetext{
${ }^{13}$ Concebido como la primera fase de la transición del capitalismo al socialismo, el modelo de desarrollo extensivo consistía en incrementar el número de trabajadores industriales transfiriendo la fuerza de mano de obra agrícola a los centros industriales; construir nuevas plantas equipándolas con nueva maquinaria; y desarrollar recursos naturales no explotados 0 nuevos territorios (Lavigne, 1995)

${ }^{14}$ El número de países que representaban el $80 \%$ de las ventas al exterior aumentó de 6 en 1988 hasta 13 en 1998 (ONE, varios años).

${ }^{15}$ Según información ad hoc obtenida en entrevista realizada el 5 de marzo del 2011.
} 
Palacios, Juan Carlos. La reforma de la economía cubana. Evaluación de su potencial impacto en el crecimiento económico.

La aceleración del crecimiento de las exportaciones a partir de 2004 se explica en base a dos hechos fundamentales: el incremento de los precios internacionales de productos estratégicos para el país como el níquel o el tabaco $^{16}$ y los acuerdos comerciales asumidos en el marco de la Alianza Bolivariana para los Pueblos de Nuestra América (ALBA). En virtud de dichos acuerdos Cuba exportaba servicios profesionales (principalmente a Venezuela) e importaba petróleo venezolano en condiciones preferenciales ${ }^{17}$. La mayor de las Antillas obtenía de esa forma tres millones de toneladas de petróleo anuales, el $80 \%$ a precios de mercado mundial a noventa días y el $20 \%$ restante calculado a partir del precio medio anual del petróleo pagadero entre 5 y 20 años (Mesa-Lago, 2003: 3).

En consecuencia, las exportaciones de servicios profesionales (principalmente servicios médicos) crecieron entre 2003 y 2007 a un ritmo del 46,6\%, pasando a representar el $48 \%$ del total de las exportaciones cubanas de bienes y servicios en 2007 y permitiendo por primera vez en la historia revolucionaria, la obtención de superávits en cuenta corriente para los años 2004, 2005 y 2007 (Quiñones, 2010: 4).

En los últimos años, la propagación de la crisis económica internacional ha supuesto un nuevo revés para el comercio exterior cubano. A pesar de que el sistema financiero cubano no estaba expuesto a la comercialización de activos tóxicos, la falta de crédito internacional y la contracción del PIB mundial de los últimos años, han afectado al ritmo de crecimiento de las exportaciones y a la renta nacional del país caribeño que se contrajo en 2009 en más de un 1,5\% (ONE, 2009). A ello, habría que sumar el impacto que para las finanzas cubanas tuvo el paso de los huracanes Gustav e $\mathrm{lke}^{18}$ y el deterioro de los términos de intercambio, que empeoraron un 38\% en el año 2008 (ONE, varios años). Como consecuencia, ese mismo año el déficit fiscal pasó a representar un $6,1 \%$ del PIB y la deuda externa aumentó en un 11,2\% (Comisión Económica para América Latina y el Caribe, varios años).

Los mayores compromisos de deuda externa y menores flujos de financiamiento externo han generado a su vez un exceso de demanda de divisas a cambio de pesos convertibles. Un desequilibrio que no ha sido ajustado mediante una devaluación hasta marzo del 2011. El déficit en la Balanza de Pagos agravado por la crisis global y una política cambiaria rígida terminó afectando al sistema de pagos y al funcionamiento de los bancos. El exceso de demanda de divisas ha provocado que desde 2008, se hayan producido demoras considerables de las transferencias bancarias, en especial cuando éstas llevaban aparejadas la compra de divisas con pesos convertibles.

\footnotetext{
16 Durante la década de los noventa e inicios de este siglo, los precios del níquel apenas oscilaron entre cuatro mil y nueve mil dólares por tonelada, como promedio anual, mientras que a partir del 2004 se registraron sus mayores cotizaciones con promedios anuales de 13823, 14744, 24254 y 38092 dólares/tonelada respectivamente (Chuairey, 2008: 77).

17 La República Bolivariana de Venezuela constituye el principal receptor de las exportaciones cubanas de servicios profesionales. En 2007 por ejemplo, recibió el 78\% del total de colaboradores cubanos en el exterior. (Quiñones, 2010: 11)

${ }^{18} \mathrm{Se}$ estima que las pérdidas alcanzaron los 5.000 millones de dólares (El mundo, 2008).
} 
Palacios, Juan Carlos. La reforma de la economía cubana. Evaluación de su potencial impacto en el crecimiento económico.

\subsection{El marco regulatorio como restricción de oferta al crecimiento económico cubano}

El debate en torno al papel de las relaciones monetario mercantiles dentro del modelo economico cubano o su encaje del plan central han ido definiendo los límites de un marco regulatorio flexible en el que pueden identificarse diferentes niveles de centralización económica desde el triunfo de la revolución.

El periodo comprendido entre 1959 y 1970, se caracterizó por un elevado nivel de centralización económica. Es en esta primera etapa cuando se llevan a cabo los cambios más profundos en la estructura del modelo político, económico y social cubano. Una de las primeras y más simbólicas medidas aprobadas durante los primeros años fue la reforma agraria. El modelo cubano comenzaba de esa forma a diseñarse en base a dos pilares fundamentales: la propiedad social de los medios de producción (representada a través del Estado) y la planificación centralizada como mecanismo de asignación de recursos. En la práctica dichos fundamentos se plasmaron en una mayor centralización de las decisiones económicas, articuladas en planes y balances materiales elaborados de forma periódica por el gobierno.

Durante la segunda mitad de los 60 puede identificarse el periodo de mayor centralización económica. Bajo el impulso del Sistema de Registro Económico se debilitó el papel del salario, se eliminaron los cobros y los pagos entre empresas socialistas, se estimularon los horarios de conciencia y las gratuidades, se desvirtuó la contabilidad y la planificación de costos y financiera, a la vez que se ponía en marcha la mayor ofensiva nacionalizadora, que permitió que a finales de los 60 , todo el comercio al por mayor y exterior, la banca, gran parte del transporte, la industria, la construcción, el $52 \%$ del comercio minorista, así como más de la tercera parte de la agricultura, se encontraran en manos del Estado (Cabarrouy, 1999: 10).

La siguiente quincena (1970-1985), daría paso a un nuevo sistema de Dirección Económica. Con la entrada de Cuba en el Consejo de Ayuda Mutua Económica, el país adaptó su modelo económico a las prácticas aplicadas en el resto de países del bloque socialista, con un mayor nivel de descentralización económica. El nuevo sistema reconocía categorías hasta entonces marginales o inexistentes como precio, costes, ganancia, crédito o rentabilidad, medía los gastos en función del valor, incorporaba fondos descentralizados en las empresas, enfatizaba el papel del estímulo material y autorizaba la creación de los Mercados Libres Campesinos ${ }^{19}$ y las Asociaciones Económicas con capital extranjero. En la práctica sin embargo, el exceso de burocratización y de centralización en la toma de decisiones frustró el objetivo de incrementar los niveles de eficiencia (El Gráfico 2 muestra que para el periodo 1986-1990 la productividad del capital se reduce de forma sostenida).

El III Congreso del PCC, celebrado en 1985, volvía a impulsar nuevamente las posiciones más favorables a la centralización económica. En un contexto en el

19 En 1980 el gobierno cubano abría un espacio de consumo liberado, en el que los campesinos privados podían acudir con sus excedentes y venderlos a precios determinados por la interacción de la oferta y la demanda. 
Palacios, Juan Carlos. La reforma de la economía cubana. Evaluación de su potencial impacto en el crecimiento económico.

que las relaciones con el CAME se habían endurecido, fijaba como objetivos prioritarios el "restablecer la capacidad de pagos del país, el ahorro de los recursos disponibles, la promoción de nuevos fondos exportables y la sustitución de importaciones" (Pérez Villanueva, 2010: 12). Esta nueva etapa, conocida como Proceso de Rectificación de Errores, corregia el Sistema de Dirección e implantaba el Sistema de Dirección y Planificación de la Economía mutilado. Entre las principales medidas recentralizadoras destacaron la limitación de la autonomía operativa y financiera de las empresas (desaparecían los fondos descentralizados), el cierre de los Mercados Libres Campesinos o cambios en materia laboral y salarial, que promovieron la creación de nuevas formas laborales como los contingentes o el trabajo voluntario, en las que se recuperaba la prevalencia de la estimulación moral sobre la material.

La desintegración del bloque socialista en 1990 desencadenó una crisis sin precedentes que paralizó la economía cubana y puso al sistema al borde del colapso. La gravedad de la crisis obligó al gobierno cubano a emprender con urgencia un programa de reformas no deseado pero impostergable. Se abría de esa forma una nueva etapa en la historia de la revolución cubana y de su modelo de dirección económica. Entre 1992 y 1999 se llevó a cabo un programa de reformas estructurales, que liberalizaron y descentralizaron espacios de la economía hasta entonces planificados centralizadamente, con el doble objetivo de incrementar la eficiencia y reinsertar al país en la economía internacional. Entre las medidas adoptadas destacaron el fin del monopolio del comercio exterior, el impulso a la Inversión Extranjera, la reorganización del sector agropecuario (con la creación de cooperativas agropecuarias y la reapertura de los Mercados Libres), la autorización del trabajo por cuenta propia, la despenalización de la tenencia y uso del dólar, la creación de una red de Tiendas de Recuperación de Divisas (TRD), la extensión del perfeccionamiento empresarial a la esfera civil de la economía y la adaptación de la planificación a las nuevas condiciones, disminuyendo su componente material en favor de un mayor componente financiero.

Sin embargo, el cambio de rumbo emprendido a principios de los 90 , no solo no fue profundizado en la siguiente década, sino que fue revertido parcialmente. Por enésima vez, el gobierno cubano volvía a recorrer en sentido inverso el camino atravesado, centralizando nuevamente aspectos claves de la economía. La consolidación de la recuperación y las mejores perspectivas financieras y comerciales que supusieron los acuerdos con China y Venezuela en la pasada década, abrían un nuevo escenario financiero, que el gobierno cubano aprovechó para acometer importantes inversiones en infraestructuras (mejoras en la generación eléctrica y en el transporte principalmente) y reactivar los grandes programas sociales bajo el marco de la denominada Batalla de las Ideas.

La financiación de estos programas requirió aumentar el volumen de divisas en manos del Estado, desarrollando mecanismos centralizados para su recuperación. Entre las principales medidas en esa dirección estuvieron la resolución 65/03 de julio del 2003 (mediante la que se establecía el Peso 
Palacios, Juan Carlos. La reforma de la economía cubana. Evaluación de su potencial impacto en el crecimiento económico.

Convertible o $\mathrm{CUC}^{20}$ como único medio de pago entre entidades cubanas), la aprobación de un gravamen del $10 \%$ a la compra en efectivo de CUC con dólares, la prohibición como norma general de los depósitos en dólares por parte de las empresas mixtas y extranjeras, la creación de una cuenta única de divisas controlada por el Estado, el establecimiento de la Comisión de Asignación de divisas (este órgano, no operativo en la actualidad, debía autorizar en un primer momento, cualquier transacción monetaria superior a 5000 CUC), la recentralización del comercio exterior ${ }^{21}$, el reordenamiento de la Inversión Extranjera Directa, las mayores restricciones impuestas al trabajo por cuenta propia, la eliminación de los fondos empresariales o la pérdida de autonomía financiera recogida en el nuevo reglamento del perfeccionamiento empresarial (Decreto Ley 281 del 2007).

Un dato que ilustra de forma clara la recentralización de la política económica cubana durante esos años es el crecimiento del consumo social del gobierno, que pasó de representar un 21\% del PIB en 2003 a un 33,9\% del PIB en 2004 (ONE, varios años).

La llegada de Raúl Castro al poder a principios del 2008, ha significado el último giro en la concepción del modelo de dirección económica. Los cambios se iniciaron en 2008 con la aplicación de esquemas de financiacion más descentralizados en aquellas producciones vinculadas a la exportación (esquemas cerrados ${ }^{22}$ en el turismo, níquel, tabaco o ron) o con capacidad de sustituir importaciones (entrega de tierras en usufructo mediante el Decreto-Ley 259 del 2008 o la apertura de mercados de insumos con el objetivo de incrementar la producción agropecuaria) y han culminado con la celebración del VI Congreso del PCC.

La revisión de la historia económica cubana muestra por tanto que el camino hacia la descentralización económica, no es un reto nuevo para el país. En esta ocasión está por ver el alcance de las medidas propuestas y si los objetivos de descentralización acabarán traduciéndose en avances reales en esa dirección. Mientras tanto parece pertinente preguntarse si los procesos de centralización y descentralización impulsados en el pasado, tuvieron algún tipo de incidencia en la eficiencia global o en el producto de la economía cubana. Con ese objetivo se sintetizan en el Cuadro 1 los resultados de los trabajos empíricos que han estimado la descomposición del crecimiento para el caso cubano.

Una primera conclusión en la que coinciden las estimaciones de los tres estudios es que la recuperación de los 90 fue posible gracias a la mejora de la Productividad Total de los Factores y no a la expansión de los factores productivos. La literatura sobre crecimiento descompone tradicionalmente el incremento de la PTF en ganancias de eficiencia y ganancias asociadas al

\footnotetext{
${ }^{20}$ En 1994 Cuba sustituyó los dólares en circulación por el CUC o peso convertible. La nueva moneda, respaldada por reservas en dólares en el Banco Central, nace con el objetivo de otorgar a éste un mayor margen de maniobra en política monetaria.

${ }^{21}$ Las empresas autorizadas a importar pasaron de 192 en 2001 a 82 en 2009. Durante el mismo periodo las empresas autorizadas a exportar se redujeron de 176 a 99 (datos facilitados por el Departamento de Teoría Económica de la Universidad de la Habana).

${ }_{22}$ Estos concedían un presupuesto en divisas a las empresas para que éstas operaran de forma autónoma.
} 
Palacios, Juan Carlos. La reforma de la economía cubana. Evaluación de su potencial impacto en el crecimiento económico.

progreso técnico. En el caso cubano, parece ciertamente improbable que la mejora de la PTF pueda ser explicada en base en una gran medida por el avance del progreso técnico, pues ni hubo durante el periodo un mayor esfuerzo inversor por parte del Estado cubano en Ciencia y Tecnología ${ }^{23}$ ni un cambio en la estructura de importaciones en la que ganaran peso los productos de alto valor tecnológico ${ }^{24}$.

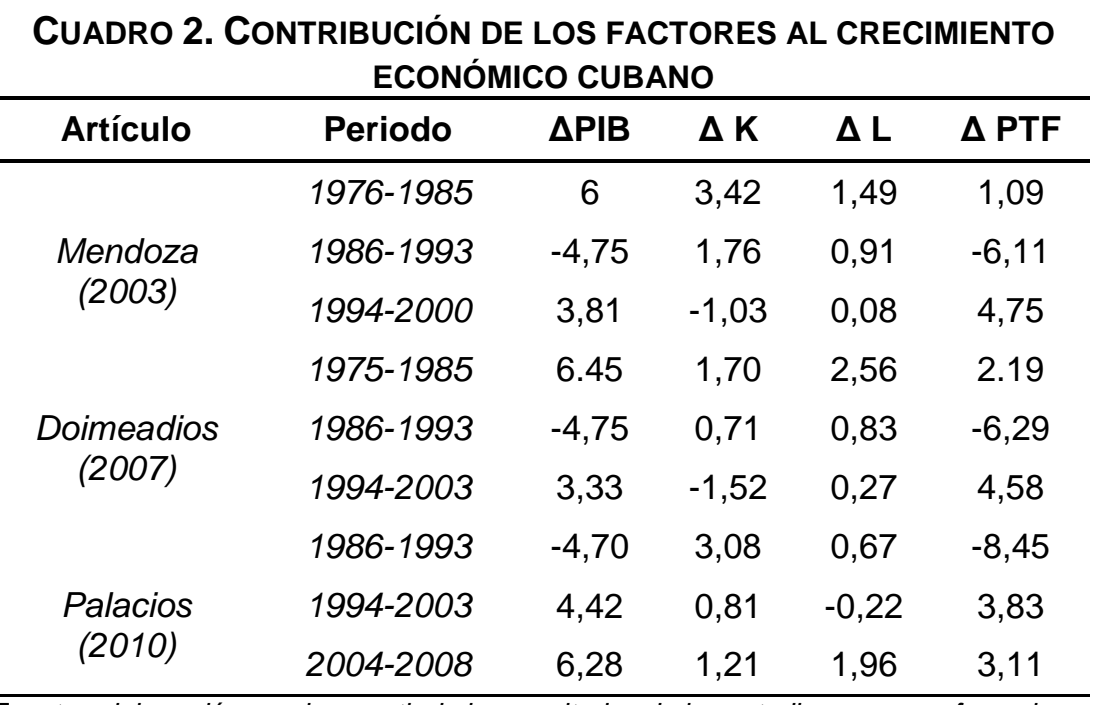

Fuente: elaboración propia a partir de los resultados de los estudios que se referencian.

Podríamos estar pues ante un primer indicio de que los cambios regulatorios aplicados entre 1994 y 2000 permitieron un uso más eficiente de los recursos disponibles en la economía cubana. Igualmente, los resultados coinciden en señalar el periodo 1986-1993, con un mayor nivel de centralización económica, como el periodo con el peor comportamiento de la productividad global de la economía. Adicionalmente, en Palacios (2010), el único estudio que incluye la reciente recentralización parcial de la economía, se muestra para este periodo un debilitamiento de la contribución de la PTF al crecimiento, respecto de la etapa anterior.

Un segundo argumento puede encontrarse en los trabajos empíricos que han estudiado la relación entre marco regulatorio y eficiencia. Tanto Doimeadios (2007) como Palacios (2010), confirman a partir de la regresión de un modelo econométrico, la hipótesis según la cual el marco regulatorio estaría influyendo en la evolución de la PTF cubana.

El primer trabajo, realizado para el periodo 1980-2006, introduce como variables explicativas de la PTF un índice sintético que aproxima el nivel de centralización de la economía ${ }^{25}$, una proxy del cambio estructural y una

\footnotetext{
${ }^{23}$ Durante el periodo 1986-1999 los gastos en ciencia y tecnología se mantiene estables en torno a los 120 millones de pesos (CEPAL, varios años).

${ }^{24}$ La caída abrupta de la necesidad de divisas hizo que la estructura de las importaciones estuviera mayoritariamente compuesta por bienes de primera necesidad. Durante la década de los 90 cerca del $80 \%$ de las divisas se dedicaban a la compra de alimentos, medicamentos y combustible (ONE, varios años).

${ }^{25}$ En su construcción, la autora utiliza la técnica de componentes principales y considera una serie de proxys de autonomía empresarial (subsidio por pérdidas a las empresas con respecto al PIB corriente y cantidad de empresas con permiso a importar), de autonomía territorial
} 
Palacios, Juan Carlos. La reforma de la economía cubana. Evaluación de su potencial impacto en el crecimiento económico.

variable que aproxima el grado de apertura de la economía cubana. El segundo trabajo utiliza como explicativas, variables que aproximan individualmente cada uno de los principales cambios regulatorios aplicados durante el periodo 19862009 , encontrando una correlación positiva entre la extensión de mecanismos de mercado y la vinculación con la divisa y la PTF de la economía cubana.

Entre las principales limitaciones de ambos estudios destacan el reducido número de observaciones con el que trabajan y la propia estimación de la serie de la PTF a partir de una función de producción agregada en la que no se incluyen las proxys de las reformas regulatorias, que sin embargo sí se consideran significativas en la explicación de las mejoras de eficiencia de la economía. A ello, habría que añadir la falta de homogeneidad de las estadísticas cubanas, lo que sin duda resta cierta confiabilidad a los resultados obtenidos. A pesar de las reservas con las que hay que interpretar dichos resultados, el hecho de que ambos trabajos hayan contrastado econométricamente la restricción que supone el marco regulatorio para el crecimiento económico cubano, refuerza la hipótesis de la que parte el análisis del VI Congreso del PCC desarrollado en la segunda parte del presente artículo.

La Productividad Total de los Factores, tanto en su forma paramétrica como no paramétrica, ha sido utilizada comúnmente en la literatura como medida del nivel de eficiencia de una economía. En el presente trabajo no obstante, se opta por considerar la productividad del capital como aproximación del nivel de eficiencia de la economía cubana. Entre las razones que justifican dicha elección se encuentra el elevado nivel de subempleo de la economía cubana, lo que introduciría una distorsión importante en el cálculo de cualquier indicador de productividad calculado a partir de las series oficiales de empleo ${ }^{26}$.

En el Gráfico 1 se compara el índice de centralización económica calculado en Doimeadios (2007) con la productividad del capital de la economía cubana para el periodo 1986-2006. La serie de stock de capital, utilizada en el cálculo de la productividad del capital, ha sido calculada a partir del método de inventarios permanentes, utilizando la metodología propuesta en Olivera y García (2004):

$$
K_{t+1}=K_{t}(1-\lambda)+I_{t}
$$

donde $\lambda$ es la tasa de depreciación promedia de la economía cubana (ONE, 1988), It representa la Formación Bruta de Capital Fijo (ONE, varios años) en el año $t$ y $K_{t}$ es el stock de capital en el año t. El dato inicial del stock de capital se toma del Anuario Estadístico de Cuba de 1986, calculado a partir del censo general de activos fijos realizado por la Junta Central de Planificación desde

(porcentaje de gastos corrientes de la actividad presupuestada que se distribuyen de manera provincial) y del tamaño del sector privado (consumo de los hogares con respecto al total de gastos corrientes de la actividad presupuestada, porcentaje de ocupados en el sector estatal con respecto al total de ocupados y porcentaje del consumo tradicional con respecto al consumo total de los hogares).

${ }^{26}$ La política de pleno empleo promovida por el gobierno cubano explica que a pesar de que el producto cayó durante los primeros años de los 90 en más de un 35\%, la tasa de desempleo no sobrepasara en ningún momento el 8\% (CEPAL, varios años). 
Palacios, Juan Carlos. La reforma de la economía cubana. Evaluación de su potencial impacto en el crecimiento económico.

1975. Dada la importante subutilización del capital durante la crisis derivada de la falta de insumos productivos y combustible (en su mayoría importados), se procede a corregir éste por su grado de utilización a partir del consumo eléctrico sectorial (ONE, varios años).

GRÁfico 2. Índice de CENTRALIZACIÓN ECONÓMICA vs PIB/K 1986-2006a

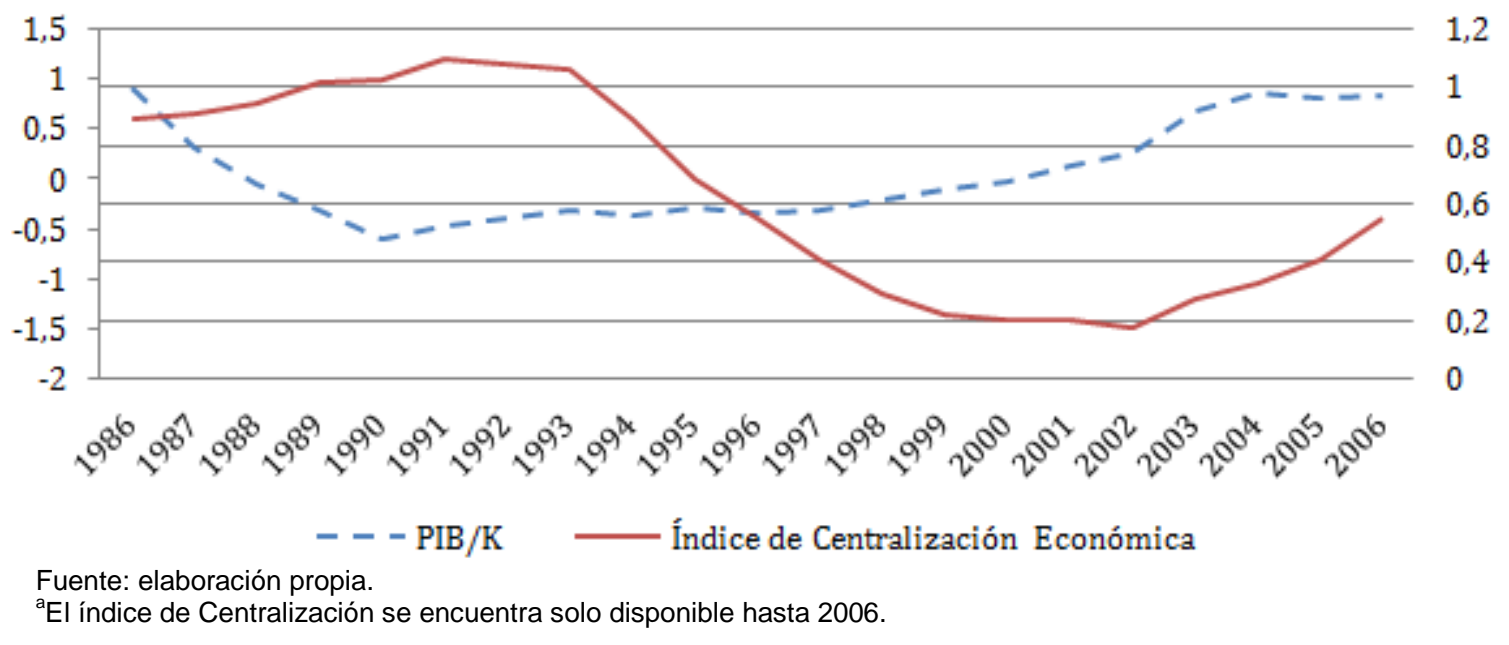

Ambas series muestran una evolución inversa en el tiempo, de lo que podría deducirse que a mayor nivel de centralización económica menor nivel de eficiencia en el uso del stock de capital. Durante el Proceso de Rectificación de Errores (1986-1990) aumentó la centralización y disminuyó la eficiencia de la economía. La descentralización del periodo 1991-2003 permitió recuperar los niveles de eficiencia de mitad de la década anterior, para estancarse en los últimos años del periodo considerado, coincidiendo con la reversión parcial de algunas de las medidas de liberalización y descentralización impulsadas tras la desaparición de la URSS.

\section{GRÁFico 3. ÍNDICE DE CENTRALIZACIÓN ECONÓMICA VS SUBVENCIÓN POR PÉRDIDAS EMPRESARIALES. EN MILES DE PESOS}

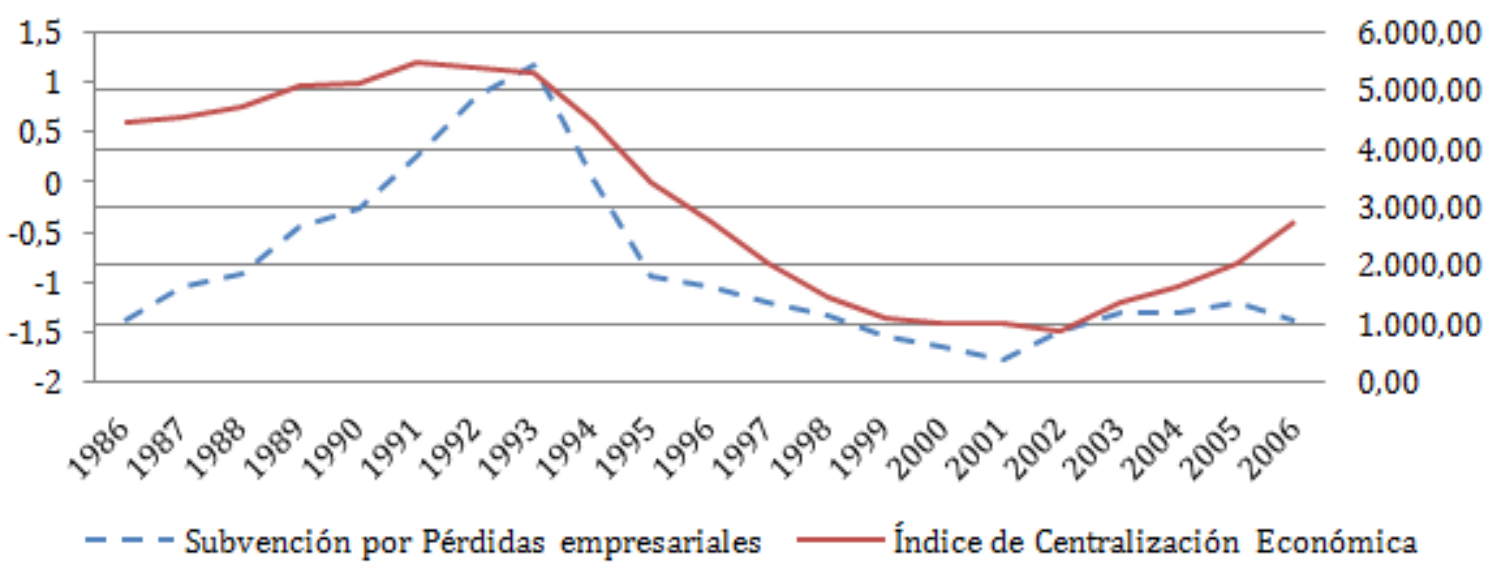

Fuente: datos ONE y Doimeadios (2007). 
Palacios, Juan Carlos. La reforma de la economía cubana. Evaluación de su potencial impacto en el crecimiento económico.

Adicionalmente el Gráfico 3 compara el Índice de Centralización Económica con los subsidios a las pérdidas de las empresas estatales ${ }^{27}$, al poder considerarse éstas como una aproximación de la eficiencia con la que opera el sistema empresarial cubano.

Las pérdidas empresariales se reducen de forma sostenida hasta el año 2001, coincidiendo con el mayor impulso descentralizador de las reformas. A partir de ese año se invierten ambas tendencias incrementando el nivel de centralización de la economía y las pérdidas empresariales. La evolución de ambas variables sugiere nuevamente cierta correlación entre el grado de centralización de la economía cubana y el nivel de eficiencia de ésta. Resulta ciertamente llamativo que 2005, un año con crecimiento del PIB y de las exportaciones a tasas de dos dígitos, sea también el año en el que se alcanzan los mayores niveles de pérdidas empresariales, lo que podría estar dando una idea del grado de desconexión entre las exportaciones de esos años y el aparato productivo cubano.

El análisis de los últimos 25 años parece apuntar por tanto, a una posible influencia de las reformas regulatorias en el crecimiento de la eficiencia y del PIB cubano. La aceptación de dicha hipótesis, aumenta el interés de analizar el efecto que las diferentes reformas reguladoras llevadas a cabo en el pasado pudieron tener sobre el crecimiento de la eficiencia y el producto de la economía cubana.

\subsubsection{La expansión de formas de propiedad no estatal}

En el caso de Cuba, se asumió desde el inició la receta soviética que equiparaba propiedad social con propiedad estatal. La gravedad de la crisis de los noventa hizo necesario introducir modificaciones en el régimen de propiedad con el doble objetivo de incrementar la producción agropecuaria y aligerar un sector estatal, incapaz en las nuevas condiciones de dar trabajo al conjunto de la población activa. Las reformas precisaron modificar la Constitución de la República en 1992. Un año más tarde se crearon mediante el Decreto Ley 142 las Unidades Básicas de Producción Cooperativa (UBPC). Los productores pasaban a ser dueños de los medios de producción que compraban a crédito y del excedente que les quedaba después de cumplir con las obligaciones del acopio estatal, pudiendo comercializar con éste en el mercado agropecuario.

Como resultado de la reestructuración del sector, el porcentaje de tierra en manos de formas no estatales de propiedad pasó de poco más del $20 \%$ en 1992 al 73\% en 1993 (ONE, varios años). Las nuevas formas de propiedad promovían una mayor vinculación del campesino con la tierra y la generación de nuevos incentivos, como vender el excedente productivo en el mercado agropecuario o participar en los beneficios de las cooperativas.

Como consecuencia, los rendimientos mejoraron, siendo el sector privado quien capitalizó la mayor parte de la recuperación productiva. Sin embargo, el

${ }^{27}$ En esta partida se incluyen las transferencias realizadas por el gobierno cubano a las empresas estatales cuando éstas no consiguen cubrir los gastos con sus ingresos. 
Palacios, Juan Carlos. La reforma de la economía cubana. Evaluación de su potencial impacto en el crecimiento económico.

pobre desempeño económico de las nuevas formas cooperativas ${ }^{28}$, evidenció al poco tiempo las limitaciones y dificultades a las que tendría que hacer frente el sector. En la práctica, las posibilidades de las nuevas cooperativas de incrementar la producción eran tan escasas, que difícilmente podían vender excedentes en el mercado agropecuario ${ }^{29}$. La participación en los beneficios tampoco resultaba un incentivo efectivo cuando el porcentaje de UBPC rentables era minoritario.

Entre las principales dificultades que explican sus pobres resultados se encuentran: la obligación de vender al Estado la mayor parte de su producción a precios que en la mayoría de los casos no cubrían siquiera los costes, la falta de autonomía real, anticipos poco estimulantes o el hecho de estar fuertemente endeudadas por la adquisición de unos medios de producción que en su mayoría se encontraban en mal estado.

Con el Decreto-Ley 141/93 se regulaba nuevamente el trabajo por cuenta propia. El sector cuentapropista mostró en los primeros años un importante dinamismo en la generación de empleos, alcanzando su máximo en 1995 con 208.746 trabajadores (Cabarrouy, 1999: 19). A partir de entonces, su número comenzó a disminuir como consecuencia de una política más restrictiva por parte del gobierno en la autorización de licencias ${ }^{30}$ y por la saturación de una oferta reducida a un limitado número de actividades.

La autorización del trabajo por cuenta propia en los 90, contribuyó a la mejora de la productividad de la economía cubana por una doble vía: por un lado, mejoró la eficiencia productiva al permitir que miles de trabajadores subempleados en el sector estatal y con escasa respuesta productiva pasaran al sector privado a ofertar una serie de servicios, que el Estado no era capaz de proveer ni en la cantidad ni con la calidad requeridas; por otro lado, la nueva ley mejoraba la estructura de incentivos de unos trabajadores que disfrutarían desde entonces de una mayor vinculación entre sus ingresos y su trabajo. En 2010, se aprobó una nueva ley sobre el trabajo por cuenta propia que superaba algunas de las anteriores limitaciones, al incluir la contratación de trabajadores fuera del núcleo familiar, el arrendamiento de espacios para su ejercicio, la ampliación del listado de oficios, las relaciones económicas con el sector estatal, el acceso a créditos bancarios o el anuncio de la creación de mercados de insumos a precios mayoristas para este tipo de trabajadores.

\subsubsection{Expansión de la Inversión Extranjera Directa}

Las posibilidades de financiación de la economía cubana (excluida de Organizaciones Económicas Internacionales como el Fondo Monetario Internacional, el Banco Mundial o el Banco Interamericano de Desarrollo desde la instauración del bloqueo estadounidense) se agravaron a finales de los

\footnotetext{
${ }^{28}$ En 1996 el porcentaje de UBPC's irrentables ascendía al 85\% en la agricultura cañera, al $70 \%$ en la no cañera y el $80 \%$ en el sector ganadero (Nova 1998: 4).

${ }^{29}$ En 1997 la participación de las UBPC en el MA era inferior al 4,8\% para los productos agrícolas y al 0,1\% para los productos ganaderos (Nova 1998).

${ }^{30}$ Mientras que en 1996 se aprobaban el $80 \%$ de las licencias, en el año 2000 este porcentaje se redujo al 25\% (Pérez Izquierdo 2003: 9).
} 
Palacios, Juan Carlos. La reforma de la economía cubana. Evaluación de su potencial impacto en el crecimiento económico.

ochenta, con el deterioro de las relaciones con el CAME, la suspensión de pagos del país y posteriormente, con la desaparición de la URSS ${ }^{31}$. Las necesidades financieras del país, le obligaron a reconsiderar su política de inversión extranjera y buscar en el capital foráneo la forma de paliar el proceso de descapitalización al que se enfrentaba la economía a principios de los noventa.

Si bien ya existía una ley que regulaba la creación de empresas mixtas (Decreto-Ley 50 de 1982), no fue hasta el desencadenamiento de la crisis, que Cuba apostaría firmemente por la apertura de su economía a la Inversión Extranjera Directa (IED). La Ley de Minas de 1994 y la ley n77 de septiembre de 1995 conformaron el nuevo marco legal para la IED. Con él se abría la puerta a la participación del capital foráneo en todas las actividades de la economía con excepción de la educación, la salud y la defensa, se autorizaban los negocios con un $100 \%$ de capital extranjero, se ponía fin a la discriminación de los inversionistas por su origen, se ofrecían garantías iguales a las ofrecidas por otros países y se autorizaban las transferencias al exterior libres de impuestos y las operaciones de comercio internacional. Los avances respecto de la legislación anterior eran por tanto significativos.

A pesar de los obstáculos derivados del bloqueo, el nuevo marco regulatorio dinamizó desde su aprobación los flujos de capital extranjero. En 2002 se contabilizaban un total de 403 Asociaciones Económicas Internacionales. A partir de ese año no obstante, se lleva a cabo un reordenamiento que supuso una notable disminución de nuevas autorizaciones y la extinción de algunos de los contratos vigentes en ese momento. Como resultado, el número de Asociaciones se redujo en 2009 a 218 Asociaciones.

Después de 15 años desde la aprobación de la ley $n^{\circ} 77$ se han cumplido los tres objetivos prioritarios para los que fue impulsada: la entrada de capitales nuevos, la transferencia de tecnología y el acceso a nuevos mercados; siendo los sectores con una mayor presencia de Inversión Extranjera Directa (turismo, minería, energía y telecomunicaciones), aquellos que presentaron mayores tasas de crecimiento durante la década de los 90 (ONE, varios años). Las dificultades actuales de la IED en Cuba, son atribuibles a las propias debilidades estructurales de la economía cubana, como la desarticulación del sistema productivo, la dualidad monetaria o el escaso desarrollo de su sistema financiero.

La extensión a nuevos sectores es uno de los aspectos en los que se pueden producir avances más significativos. A pesar de que la ley no lo impide, en sectores de vital importancia como el azucarero o el financiero no se han autorizado hasta la fecha la entrada de capital extranjero, lo que podría suponer interesantes aportaciones en materia tecnológica y de know how.

\footnotetext{
${ }^{31}$ Mesa Lago (1993: 41) estima que entre 1960 y 1990 Cuba percibió créditos por valor de 25.279 millones de dólares en condiciones favorables.
} 
Palacios, Juan Carlos. La reforma de la economía cubana. Evaluación de su potencial impacto en el crecimiento económico.

\subsubsection{Redefinición de la planificación y de las funciones empresariales}

La desaparición del bloque socialista no supuso únicamente la pérdida de los principales socios comerciales de Cuba, sino también la necesidad de rediseñar un modelo que hasta entonces había gravitado sobre una base de recursos materiales y financieros garantizados. Con ese objetivo, se pusieron en marcha a principios de los noventa, reformas que perseguían una mayor vinculación entre los necesarios equilibrios macroeconómicos y el comportamiento de los agentes a nivel microeconómico.

Los dos cambios más relevantes en este sentido fueron la redefinición del sistema de planificación y la descentralización de funciones a nivel empresarial. El nuevo escenario exigió recuperar categorías hasta entonces olvidadas, como las relaciones monetario-mercantiles o los indicadores financieros. Las principales transformaciones de la planificación de la economía se concretaron en el abandono del carácter homogéneo del plan y en el cambio en los criterios de asignación de los recursos.

En abril de 1994, se inicia un proceso de reorganización de los Órganos de Administración y Control del Estado, en virtud del cual se eliminó la exclusividad del Estado en determinadas funciones que pasaron desde entonces a ser compartidas con las empresas. El proceso de descentralización no obstante, fue parcial y selectivo, lo que propició la segmentación del sistema en función de su mayor o menor dependencia del Estado y del área monetaria al que estuvieran vinculadas las empresas. Entre los diferentes tipos de empresas estatales, las sociedades mercantiles (vinculadas en su mayoría con el comercio exterior) y las empresas en perfeccionamiento empresarial, pasaron a disfrutar de una mayor autonomía operativa y financiera.

En esencia, el nuevo programa supuso una gestión más descentralizada y flexible en cuanto a la organización del trabajo, de la producción, del sistema salarial y de incentivos y de la política financiera y de inversión de la empresa, con el objetivo de incrementar su eficiencia y garantizar su autonomía financiera. Si bien no existe información actualizada sobre sus resultados, los últimos datos disponibles sugieren un comportamiento más eficiente de las empresas en perfeccionamiento que el mostrado por aquellas no incluidas en el programa $^{32}$. El año 2004 supondría sin embargo un punto de inflexión para el programa. Con la creación de la caja única y la recentralización de las divisas, el grado de autonomía de las empresas adscritas se vio profundamente afectado. Las empresas debían entregar en concepto de aporte la totalidad de sus beneficios después de impuestos, perdiendo de esa forma la autonomía para financiar gastos o inversiones en moneda convertible, que desde ese momento pasaría a ser competencia exclusiva del Estado.

\footnotetext{
32 A pesar de que en 2006 solo formaban parte del programa una de cada cuatro empresas estatales, éstas superaban en un $42 \%$ la productividad media de la economía, representaban el $59,8 \%$ de las ventas en CUC, el $64 \%$ de los aportes en esa moneda, el $52,5 \%$ de las beneficios y reducían el porcentaje de empresas irrentables desde el $38 \%$ promedio de la economía a un escaso $7 \%$ de empresas vinculadas al programa (Betancourt, 2007)
} 
Palacios, Juan Carlos. La reforma de la economía cubana. Evaluación de su potencial impacto en el crecimiento económico.

\subsubsection{La recuperación del mercado como mecanismo de asignación de recursos}

La primacía del plan en la asignación de recursos ha sido una de las principales señas de identidad del modelo socialista cubano. La desconexión del bloque socialista sumió al sector agropecuario, en una caída libre que contrajo su PIB entre 1990 y 1994 en más de un 50\% (ONE, varios años). La crítica situación obligó a la adopción de medidas urgentes. El 20 de septiembre de 1994, mediante la resolución conjunta del Ministerio de Agricultura y el Ministerio de Comercio Interior se autorizó la reapertura de los Mercados Agropecuarios.

Los nuevos mercados nacieron con el doble propósito de incrementar la producción y redirigir la actividad del mercado negro hacia la economía formal. Su Pueden comercializarse en ellos todos aquellos productos que excediesen la cantidad contratada con excepción de la carne bovina, la carne equina, la leche fresca y sus derivados, el café, el tabaco, el cacao, la papa y el huevo de gallina.

En 1995, tras cinco años de contracción de la producción agropecuaria, el sector consiguió revertir la tendencia e iniciar la recuperación, acumulando un crecimiento del $20 \%$ en los siguientes tres años (ONE varios años). Otro importante logro atribuible también en parte a la creación de los Mercados Agropecuarios, fue la rápida depreciación del dólar en el mercado informal, que pasó de 120 pesos por dólar en julio de 1994 a 35 pesos por dólar en junio del siguiente año (Deere, 1995: 15).

Sin embargo, el pobre desempeño del sector (según datos de la ONE La tasa de crecimiento promedio para el periodo 1995-2009 fue del 1,96\%) sugiere que las medidas adoptadas para su reestructuración han sido insuficientes. En este sentido, resulta interesante analizar algunos de los factores que hacen que el actual mercado agropecuario no sea un estímulo suficiente para incrementar la producción de los agricultores y ganaderos cubanos.

Para la empresa estatal, el incentivo de participar en el mercado a precios mayores no era tal, al no participar sus empleados en las ganancias de las empresas. Además, tal y como veíamos en el punto 3.2, las cooperativas presentan serios problemas para ser rentables y cuando lo eran, la participación de los trabajadores en el beneficio no era inmediata, pues se hacía efectiva un año más tarde.

En el caso de los agricultores privados el problema resulta bien diferente. El volumen de ingresos que reciben en la actualidad es lo suficientemente alto como para no verse estimulados a incrementar su producción; máxime si se considera que no tienen la posibilidad de dedicar sus ahorros ni a la compra de bienes de equipo ni de bienes de consumo duradero (Nova, 1998).

La incorporación de mecanismos de mercado debía provocar dos importantes externalidades positivas. Por un lado debía representar un estímulo a la producción al poder realizar ésta a precios superiores a los fijados 
Palacios, Juan Carlos. La reforma de la economía cubana. Evaluación de su potencial impacto en el crecimiento económico.

centralizadamente. Por otro, el tránsito de métodos administrativos de fijación de precios a métodos basados en la oferta y la demanda debía contribuir favorablemente a la medición de variables claves para el buen funcionamiento económico y la correcta asignación de recursos. Sin embargo, en las condiciones actuales éstos siguen siendo manifiestamente insuficientes, tanto cuantitativa como cualitativamente. Por lo que se hace necesario, no solo la extensión de tales mecanismos al resto de sectores sino el perfeccionamiento de los mismos, mediante la creación de instituciones y regulaciones orientadas a garantizar una competencia efectiva en dichos mercados.

\subsubsection{Conexión con los sectores generadores de divisas}

Los primeros esquemas de autofinanciamiento empresarial en divisas datan de finales de 1991, con la creación de FINATUR, una casa financiera dependiente del Ministerio de Turismo y cuya misión principal era financiar en condiciones favorables aquellas producciones cuyo destino final era el sector turístico.

La reactivación de la industria nacional y el incremento de su participación en las compras del sector turístico y las TRD, evidenciaron la importancia que los esquemas de autofinanciamiento tuvieron en la vinculación entre el sector industrial y los sectores generadores de moneda convertible: el turismo, las TRD y el sector exportador.

El objetivo de dicha financiación era principalmente proveer de capital circulante, si bien en no pocas ocasiones esta fue utilizada para la modernización de la planta industrial receptora de la inversión. Gracias a dicho mecanismo fue posible incrementar la participación nacional en el abastecimiento de bienes y servicios al sector turístico, del $12 \%$ de mediados de los 90 al 67\% en 2005 (Pérez, 2006: 80). Cabe señalar que dicho éxito no se sustentó en el desarrollo de políticas proteccionistas sino en la creación de instituciones de apoyo y de espacios de coordinación entre el sector emergente e industrial (García, 1998: 40).

Los encadenamientos productivos se deben en parte al desarrollo de un sector con gran efecto arrastre como el turismo ${ }^{33}$, pero también a la posibilidad que se les dio a los proveedores de obtener financiación en divisas. Las empresas estatales que vendían al turismo y a las TRD obtenían financiación en moneda convertible que les permitía cerrar de forma autónoma su ciclo productivo. Ello les confería en la práctica una mayor flexibilidad y autonomía operativa que las empresas del sector tradicional, cuya disponibilidad de divisas dependía de la asignación del presupuesto estatal. Las empresas con presupuesto en moneda convertible disponían además de un mayor margen para la estimulación de sus trabajadores, lo que sin duda afectaba también de forma positiva a los niveles de motivación y productividad laboral de estas empresas.

La financiación condicionada a las ventas en divisas suponía un avance en otro aspecto de vital importancia como la disciplina financiera, al vincular los

\footnotetext{
33 "Según estudios de diferentes especialistas y organismos internacionales en materia turística, se estima que por cada empleo directo se generan de 2,7 a 3 empleos indirectos" (García 1998: 11)
} 
Palacios, Juan Carlos. La reforma de la economía cubana. Evaluación de su potencial impacto en el crecimiento económico.

créditos a la rentabilidad del proyecto y a las posibilidades de ser devueltos. Un criterio ausente en las asignaciones presupuestarias del plan.

En el Gráfico 4 se muestra la evolución de la productividad del capital comparada esta vez, no con un índice sintético de centralización económica, sino con la evolución de variables que aproximan cada una de las principales reformas descentralizadoras promovidas durante las reformas de los 90. Los datos se estandarizan restando la media y dividiendo por la desviación estándar de cada serie. Posteriormente se suma a cada variable su valor mínimo para que todos los valores de la serie puedan representarse con signo positivo. Las variables consideradas en el análisis son las siguientes:

a) Apertura a la Inversión Extranjera Directa: se utiliza el número de Asociaciones Económicas Internacionales como proxy del grado de apertura a la IED. La construcción de esta serie se ha realizado a partir de datos facilitados por el Centro de Estudios de la Economía Cubana.

b) Grado de implantación del Perfeccionamiento Empresarial (PER): esta variable es aproximada a partir del número de empresas adheridas al programa de Perfeccionamiento Empresarial. La construcción de esta serie se ha realizado a partir de Marquetti (2006) y Nova (2010).

c) Articulación con los sectores generadores de divisas (DIV): ésta se aproxima a partir de las ventas nacionales al sector turístico y a las TRD. Los datos que han permitido construir la serie han sido facilitados por el Departamento de Turismo del Instituto Nacional de Investigaciones Económicas.

d) Extensión de formas de propiedad no estatales (PRO): esta variable se aproxima a partir del número de trabajadores ocupados en el sector no estatal. Las series se construyen a partir de ONE (varios años) e información facilitada por el Centro de Estudios de la Economía Cubana.

e) Peso de los mercados liberados (MER): esta serie se aproxima a partir del peso del consumo en los mercados liberados (mercado agropecuario y del mercado por cuenta propia) respecto del consumo final de las familias. La fuente estadística utilizada ha sido ONE (varios años).

\section{GRÁFICO 4. MEDIDAS DE DESCENTRALIZACIÓN VS PRODUCTIVIDAD DEL CAPITAL}

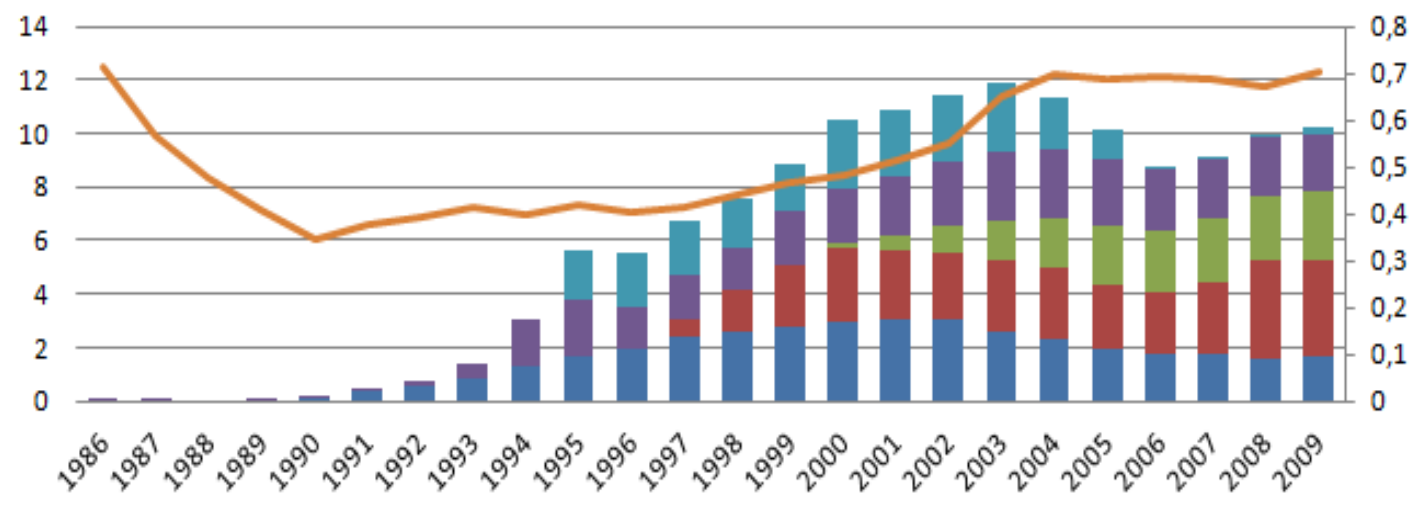

Fuente: elaboración propia.

La correlación entre la productividad del capital y las medidas de liberalización y descentralización se hace nuevamente evidente. Si la productividad del 
Palacios, Juan Carlos. La reforma de la economía cubana. Evaluación de su potencial impacto en el crecimiento económico.

capital cae durante la segunda mitad de los ochenta, en plena etapa de centralización de la economía, ésta inicia su recuperación paralelamente a la adopción de medidas de descentralización económica como las que se aproximan en el Gráfico. Éste recoge igualmente la última recentralización de la economía en 2004 (mediante el menor valor global asociado a las medidas de descentralización) y el estancamiento de la productividad del capital desde ese mismo momento.

El análisis diferenciado de las medidas aprobadas permite ver que el estancamiento de la productividad coincide con el retroceso del número de empresas con capital extranjero y del peso de los mercados liberados. A pesar de que el resto de medidas se mantienen estables desde un punto de vista cuantitativo, la aprobación de la caja única, a mediados del 2003, eliminó casi por completo la autonomía financiera de las empresas y con ella, los incentivos que habían supuesto para éstas entrar a formar parte del programa de perfeccionamiento empresarial o vender a los sectores solventes en divisas.

\subsection{Interacción de las restricciones estructurales al crecimiento económico cubano}

Tanto la evidencia empírica como el análisis bibliográfico de las últimas décadas, parecen apoyar por lo tanto la existencia de restricciones estructurales que limitan la expansión del PIB cubano.

Las características de la economía cubana, las conclusiones de los trabajos empíricos y la enorme sensibilidad que ha demostrado el PIB del país a la evolución de sus exportaciones a lo largo de las últimas décadas (mostrada en el Gráfico 1) apoyan la hipótesis según la cual, la economía cubana se encontraría restringida por el lado de la demanda por el equilibrio en la Balanza de Pagos.

El modelo de Thirlwall, en su versión más reducida, plantea que la tasa de crecimiento sostenible con el equilibrio de largo plazo de la Balanza de Pagos viene determinada por la razón entre la tasa de crecimiento de las exportaciones y la elasticidad ingreso de la demanda de importaciones. Tal y como se reflejaba en el Cuadro 1, la mayoría de los trabajos que han aplicado dicho modelo para Cuba han obtenido un valor para la elasticidad ingreso de la demanda de importaciones cercano a dos; lo que equivaldría a decir que la tasa de crecimiento sostenible con el equilibrio de la Balanza de Pagos (y) debe ser aproximadamente dos veces menor que la tasa de crecimiento de las exportaciones ${ }^{34}$. Resulta interesante analizar cuál ha sido el comportamiento de esta relación a lo largo del periodo de estudio.

El primer aspecto a destacar es el valor que adopta la serie durante el periodo previo a la desaparición de la URSS. La relación entre el crecimiento del PIB y de las exportaciones con valores cercanos a cero y diferente signo parece no

${ }^{34}$ Gran parte de los estudios aplicados a Latinoamérica (Moreno-Brid, 1998; Loría, 2001; Fugarolas y Matesanz, 2005) obtienen elasticidades menores, lo que en la práctica supone que la economía cubana se encuentra más restringida por la Balanza de Pagos, pues la expansión del PIB requiere de incrementos mayores en las exportaciones del país. 
Palacios, Juan Carlos. La reforma de la economía cubana. Evaluación de su potencial impacto en el crecimiento económico.

dibujar una relación clara entre el PIB y las exportaciones, algo coherente con la posibilidad de financiarse en ese periodo por otras vías como los créditos preferenciales procedentes de la URSS. Un segundo aspecto destacable es el elevado valor de la razón x/y para el año 1994, resultado de un crecimiento economico cercano a cero. Ese año se adoptaron medidas decisivas para la reinserción internacional del país, como la reorganización del sistema financiero y bancario nacional, la apertura de representaciones de banca comercial extranjera, la emisión del peso convertible, la autorización de formas de propiedad no estatal, la apertura de mercados agropecuarios o el fuerte impulso a la Inversión Extranjera Directa ${ }^{35}$, permitiendo un crecimiento de las exportaciones en un $27 \%$ y del PIB en un $0,6 \%$ para el año 1994. A partir de entonces se aprecia una disminución de dicha relación que lleva la razón y/x muy por debajo del valor de las elasticidades estimadas en los trabajos empíricos, alcanzando incluso para los años 1998, 2001 y 2002 valores negativos; lo que supone que la economía creció incluso en aquellos años en los que las exportaciones cayeron. Esa tendencia se mantiene hasta el año 2003, coincidiendo con la tendencia descentralizadora de la economía, lo que podría entenderse como una relajación de la restricción externa resultado de la descentralización económica. En 2003, año en que se autoriza la caja única de divisas entre otras medidas recentralizadoras, aumenta nuevamente la relación, situándose por encima de los valores estimados y sugiriendo que en los periodos de mayor centralización, la economía cubana necesita para crecer de fuertes expansiones de las exportaciones, como las logradas a partir de los acuerdos con China y Venezuela.

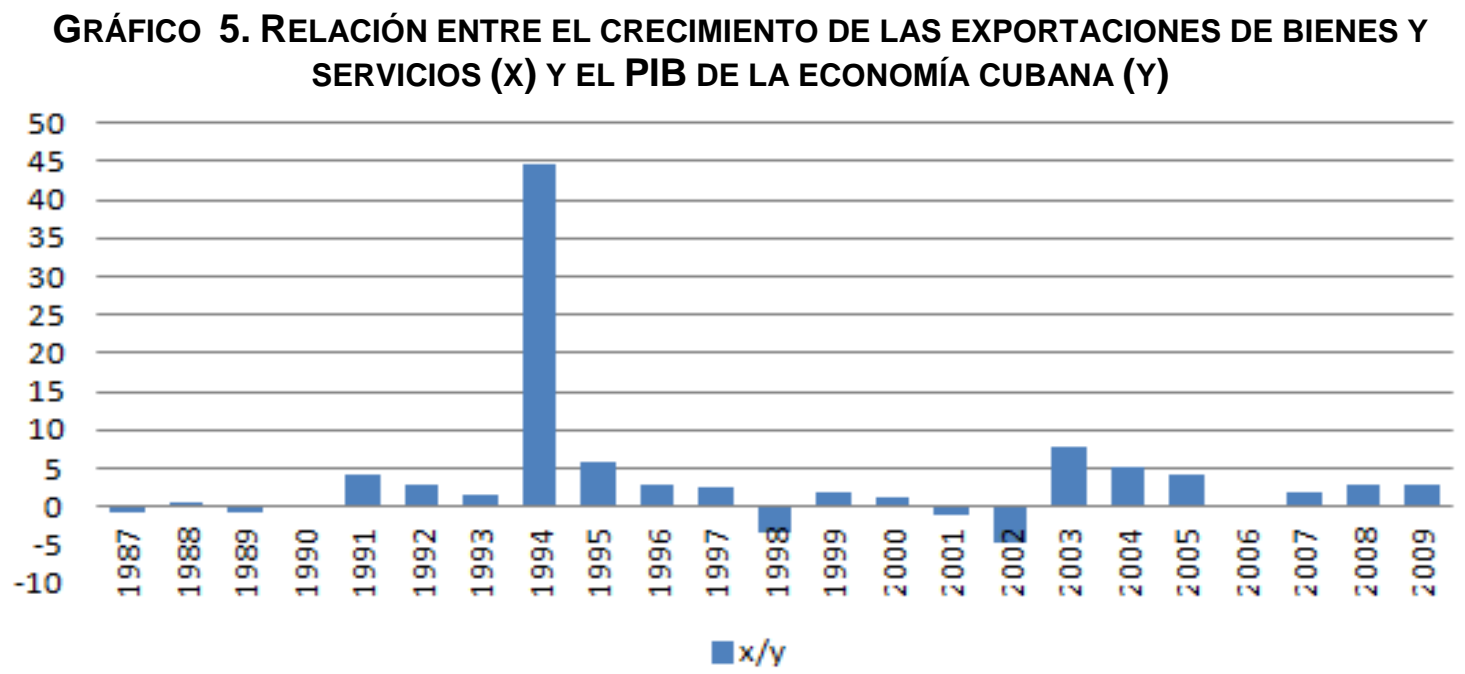

Fuente: elaboración propia.

Anteriormente, se justificaba la expansión de las exportaciones de 1994 entre otras razones, por las reformas descentralizadoras emprendidas ese año, lo que supondría aceptar impícitamente que las restricciones estructurales al crecimiento económico cubano (de oferta y de demanda) podrían estar conectadas y retroalimentarse o contrarestarse la una a la otra.

\footnotetext{
${ }^{35}$ Él número de Asociaciones con capital extranjero creció en 1994 en más de un 57\% (según datos facilitados por el Centro de Estudios de la Economía Cubana).
} 
Palacios, Juan Carlos. La reforma de la economía cubana. Evaluación de su potencial impacto en el crecimiento económico.

El Esquema 1 representa gráficamente los posibles canales de transmisión entre ambas restricciones. Tal y como se refleja, las potenciales ganancias de eficiencia derivadas de los cambios en el marco regulatorio, pueden acabar teniendo efecto, tanto en la restricción de oferta como en la restricción de demanda. Por un lado, un uso más eficiente de los recursos productivos debería acercar a la economía a su frontera de posibilidades de producción. Siguiendo el razonamiento neoclásico, el margen en el corto plazo para expandir el producto cubano, se encontraría en ese caso en la mejora de la Productividad Total de los Factores. Ésta a su vez relajaría el efecto de la restricción externa sobre el crecimiento económico cubano. El incremento de la productividad mejoraría la competitividad de las producciones cubanas, expandiendo las exportaciones y el producto y haciendo más sostenible el crecimiento del país en el largo plazo (representado en el Esquema 1 como canal de transmisión de la restricción interna al ámbito externo). ${ }^{36}$

\section{ESQUema 1. CANALIZACIÓn DE LAS RESTRICCIONES AL CRECIMIENTO CUBANO}

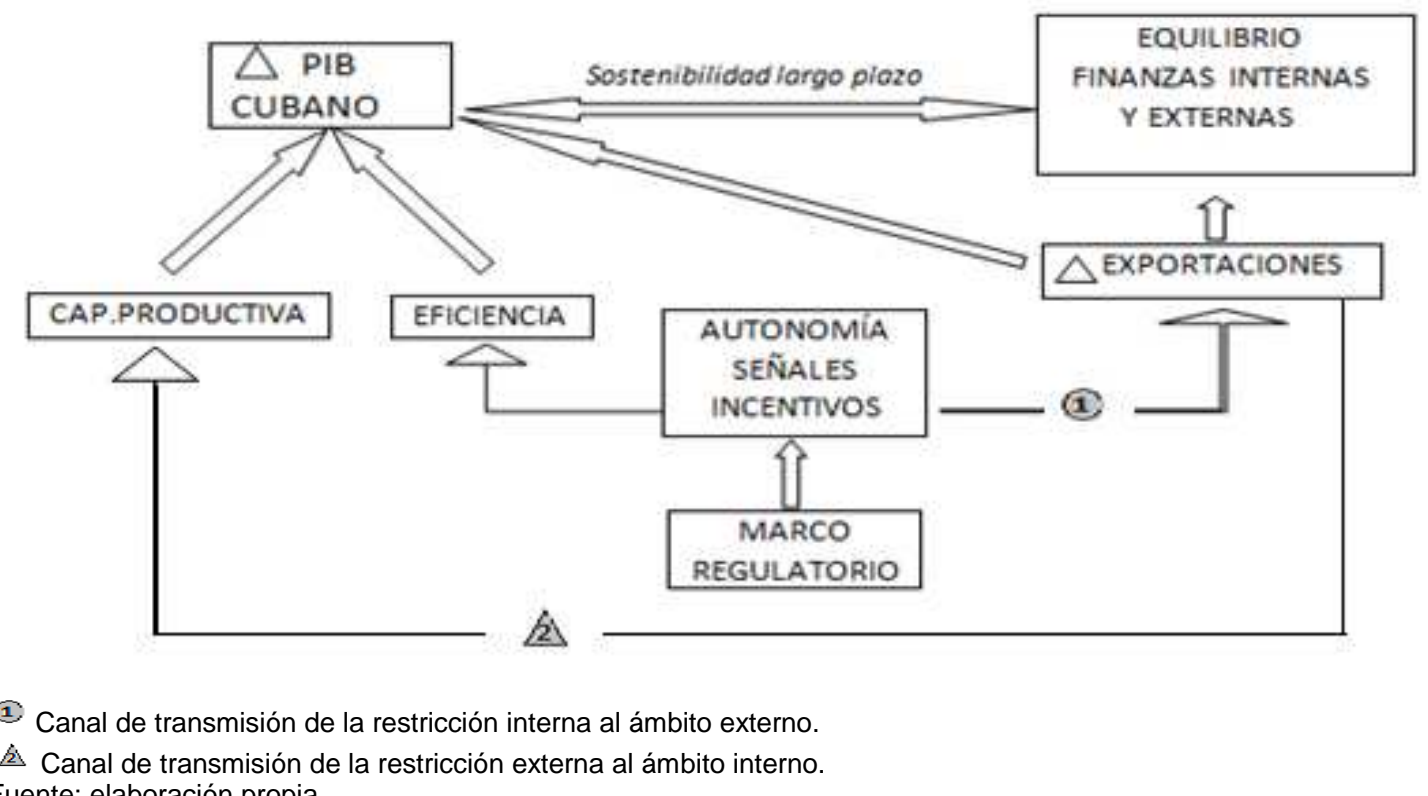

¿anal de transmisión de la restricción externa al ámbito interno.

Fuente: elaboración propia.

Las mejoras regulatorias podrían poner en marcha un círculo virtuoso al aumentar el volumen de divisas en un país con escasas posibilidades de acceder a crédito internacional y que tal y como se comentaba anteriormente, importa en su gran mayoría sus bienes de capital. Las divisas procedentes de las ventas al exterior concederían de esa forma, un mayor margen para importar bienes de equipo y ampliar la capacidad productiva de la economía cubana (representado en el Esquema 1 como canal de transmisión de la restricción externa al ámbito interno).

Dicha hipótesis cobra un mayor sentido si se considera que en una economía planificada como la cubana, el único agente inversor es el Estado, por lo que la

\footnotetext{
${ }^{36}$ Thirlwall (1979) refleja en su Modelo de Crecimiento Restringido por la Balanza de Pagos la importancia que el equilibrio externo tiene para el sostenimiento del crecimiento en el largo plazo. Posteriormente, Moreno-Brid (1998), desarrollaría una nueva versión del modelo al compatibilizar la tasa de crecimiento restringida con incrementos sostenibles de la deuda externa.
} 
Palacios, Juan Carlos. La reforma de la economía cubana. Evaluación de su potencial impacto en el crecimiento económico.

situación de las finanzas públicas puede incidir de una forma más directa e inmediata en los niveles de inversión de su economía. Con el fin de examinar la posible dependencia entre ambas variables, se representa en el Gráfico 6 la evolución de la serie de exportaciones de bienes y servicios y la Formación Bruta de Capital durante el periodo de estudio.

La evolución de ambas series muestra cierta correlación entre las variables, lo que refuerza la idea de que la restricción externa se transmite hacia el interior de la economia representado en el Esquema 1. Es destacable que los cambios de tendencia en las exportaciones se produzcan tan solo uno o dos años antes que los cambios en la serie de inversión, lo que puede estar reflejando el escaso margen del que dispone la economía cubana para ajustar su presupuesto a la disponibilidad de divisas.

\section{GRÁFICO 6. EXPORTACIONES DE BIENES Y SERVICIOS Y FORMACIÓN BRUTA DE CAPITAL 1986-2009. PRECIOS CORRIENTES}

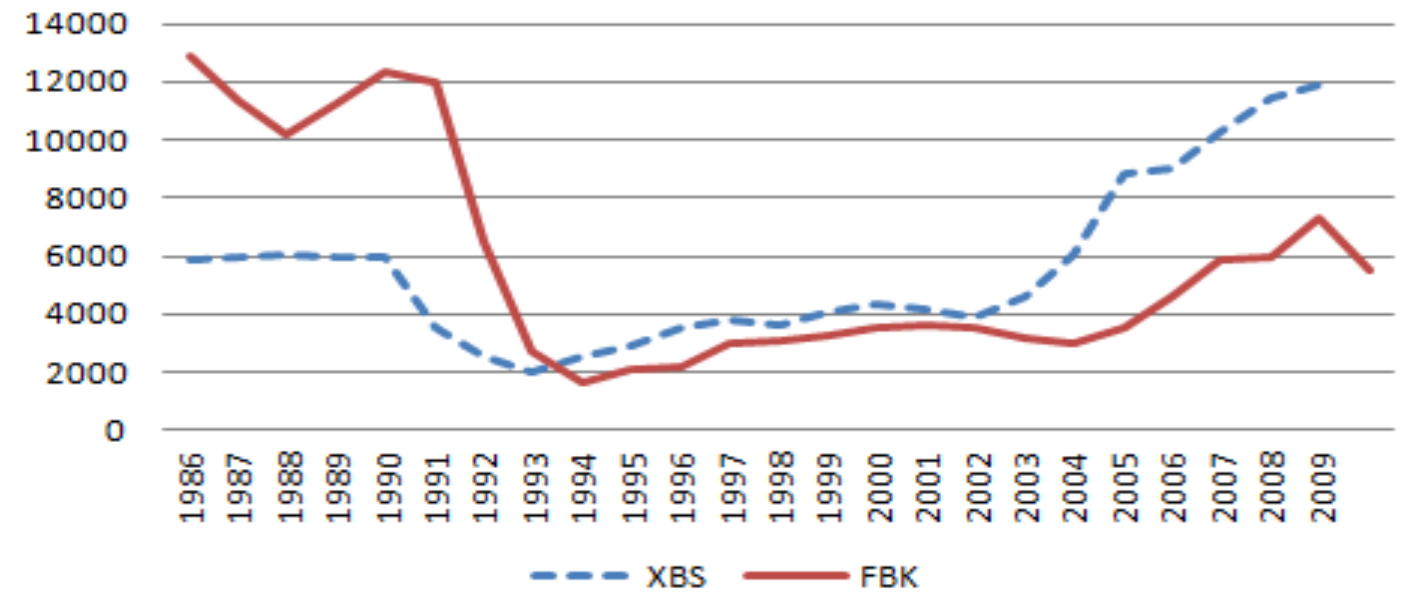

Fuente: elaboración propia a partir de ONE (varios años).

Durante el periodo de pertenencia al CAME los niveles de inversión son prácticamente el doble que las exportaciones, lo que da una idea de la existencia durante dicho periodo de fuentes de divisas alternativas a las exportaciones. El menor crecimiento de la inversión en capital a partir de 2003 puede deberse al gran volumen de recursos que el gobierno cubano dedicó durante esos años a los programas sociales vinculados con la llamada batalla de las ideas, cuyo principal objetivo era recuperar los principales indicadores sociales ante el deterioro experimentado por éstos durante la crisis de los 90.

\section{AnÁlisis de los lineamientos de la Política Económica y Social DEL VI CONGRESO DEL PCC}

El Esquema 1 vinculaba el uso eficiente de los recursos de la economía cubana, principalmente con tres variables microeconómicas: la autonomía empresarial (poder hacer), las señales microeconómicas (saber hacer) y los incentivos (querer hacer). La importancia de los cambios propuestos en el modelo económico cubano y su capacidad para incidir en el crecimiento económico y su sostenibilidad, radican en gran parte en la identificación en la nueva estrategia, de esas tres variables como palancas impulsoras de la 
Palacios, Juan Carlos. La reforma de la economía cubana. Evaluación de su potencial impacto en el crecimiento económico.

eficiencia y en la mejora de las condiciones para expandir las capacidades productivas y corregir los desequilibrios financieros. A continuación se detallan los avances planteados en cada una de dichas áreas.

\subsection{Mejora de la eficiencia de la economía}

El análisis de los lineamientos del VI Congreso del PCC permite identificar las siguientes medidas con potencial para promover la eficiencia:

\section{Medidas dirigidas a aumentar la autonomía empresarial}

- Separación de las funciones estatales y empresariales (lineamiento 6), garantizando la no intervención directa en la gestión empresarial de las diferentes Administraciones (lin.35).

- Mayor autonomía financiera para las empresas estatales, definiendo claramente las facultades y los instrumentos financieros de los que dispondrán (lin.13), descentralizando la administración del capital de trabajo e inversiones hasta el límite previsto en el plan (lin.16), eliminando el subsidio por pérdidas y los financiamientos presupuestarios como norma (lin.18) y permitiendo la creación descentralizada de fondos para el desarrollo, para inversiones y para la estimulación de los trabajadores (lin.19).

- Mayor autonomía financiera para el sector no estatal, al poder acceder a diferentes servicios y financiación bancaria (lin.53), a los que hasta ahora no tenían acceso.

- Se fija un marco más flexible para las cooperativas, según el cual podrán constituir cooperativas de segundo orden ${ }^{37}$ (lin.29), abarcar nuevos sectores y promover la autonomía de gestión (lin.180), acceder a mercados de insumos (lin.9 y 199), realizar operaciones de comercio exterior (lin.83) establecer relaciones contractuales con otro tipo de agentes estatales y no estatales (lin.27), lo que sin duda contribuirá notablemente a mejorar la articulación del segmentado sistema empresarial actual.

- Descentralización territorial: uno de los puntos más relevantes del proceso de cambios abierto en el VI Congreso del partido es el mayor peso que se pretende dar a los territorios. Con ese objetivo, se asignarán funciones estatales a Administraciones Provinciales y Municipales, sin llegar a interferir directamente en la gestión empresarial (lin.35), se promoverá el desarrollo de proyectos locales conducidos por los Consejos de Administración Municipal, la creación de micro-industrias y centros de servicios, vinculando la gestión de los mismos a entidades enclavadas en el municipio (lin.37) y otorgando un peso fundamental en la conducción de los proyectos a los Consejos de Administración Municipal. El impulso al desarrollo económico local supondrá muy probablemente la reactivación de líneas de microcréditos ya existentes como el Fondo Rotatorio para Iniciativas Económicas Locales y la conexión de la cooperación exterior con los proyectos locales.

\footnotetext{
${ }^{37}$ Unión de cooperativas de mutuo acuerdo cuyo cliente es la cooperativa.
} 
Palacios, Juan Carlos. La reforma de la economía cubana. Evaluación de su potencial impacto en el crecimiento económico.

Medidas dirigidas a mejorar las señales económicas y el ambiente microeconómico

- Endurecimiento de la restricción financiera de las empresas. Con ese fin se eliminan los subsidios por pérdidas (lin.18), se establece que las inversiones deberán financiarse con capital propio o mediante créditos externos (una vez demostrada la capacidad de la inversión para ser devuelta con sus propios resultados), se fortalece el papel del crédito bancario (lin.51) y se anuncia la liquidación de aquellas empresas con pérdidas sostenidas 0 capital de trabajo insuficiente (lin.16). Se prevé la posibilidad de que se transformen en otras formas de gestión no estatal, si bien éstas deberían ser capaces de autofinanciarse.

- Prioridad de los mecanismos económico-financieros en el control de la gestión empresarial (lin.11).

- Mayor exigencia en el cumplimiento de los contratos (lin.10).

- Fomento de la infraestructura técnica de normalización y metrología, control de calidad y de la propiedad industrial (lin.216).

- Medidas dirigidas a la fundamentación económica de la tasa de interés (lin.48).

- Revisión integral del sistema de precios, de forma que permita medir correctamente los hechos económicos, estimular la eficiencia y controlar los desequilibrios financieros internos y externos (lin.61).

- Utilización más efectiva de las relaciones monetario-mercantiles en el sector agropecuario (lin.178).

- La mayoría de precios serán fijados según la ley de la oferta y la demanda. Como norma, no habrá subsidios de precios (lin.181).

- Autorización de las relaciones contractuales entre el sector estatal y no estatal (lin.27), permitiendo una mayor articulación entre ambos sectores y del sistema empresarial en su conjunto.

Medidas dirigidas a mejorar la estructura de incentivos

- El proceso de reordenamiento laboral según el cual, un porcentaje importante $^{38}$ de la población será declarada "disponible" y podría pasar al desempleo (si no es capaz de encontrar trabajo en la esfera privada) supone un nuevo incentivo laboral hasta ahora inexistente que es el de mantener el puesto de trabajo.

- Ampliación del trabajo por cuenta propia. A parte de la mejora de incentivos que representa para este tipo de trabajadores la mayor vinculación de sus ingresos con su trabajo, la ampliación del trabajo por cuenta propia tendrá un importante efecto en los niveles de eficiencia de la economía, al permitir reducir el subempleo de la esfera estatal y mejorar en consecuencia la eficiencia en la asignación de unos recursos productivos, que al no utilizarse plenamente ven reducir su productividad. La nueva ley amplía el número de actividades a desarrollar, permitiendo por primera vez contratar trabajadores

\footnotetext{
${ }^{38}$ Oficialmente el volumen de plantillas infladas se ha cifrado en un millón de trabajadores (Cubadebate 13 de septiembre de 2010), lo que supone alrededor de un $20 \%$ de la población ocupada del 2011 (ONE, varios años).
} 
Palacios, Juan Carlos. La reforma de la economía cubana. Evaluación de su potencial impacto en el crecimiento económico.

fuera del círculo familiar y el arrendamiento de espacios para el ejercicio de la actividad.

- Vinculación de los ingresos de trabajadores y empresarios a los resultados (Lin.20 y 170). El principal avance se produce al reconocer por primera vez la importancia de los estímulos materiales para los empresarios. El compromiso con la revolución y la sociedad que el sistema ha pedido históricamente a los cuadros empresariales, ha demostrado ser un incentivo insuficiente para la asimilación de nuevas tecnologías y procesos y la mejora de los resultados de las empresas. La falta de incentivos para innovar y mejorar los resultados empresariales ha sido identificado en la literatura como uno de los problemas endémicos del socialismo real (Kornai, 1979: 1)

- Creación de fondos de estimulación salarial descentralizados a nivel empresarial (lin.19).

- Liberalización de la compra de viviendas (lin.297) y de automóviles (lin.286). La mejora del poder adquisitivo de los ingresos debe acompañarse de una oferta más diversificada y de la posibilidad de que dichos ingresos sean destinados a mejorar el consumo de las familias y no al ahorro forzoso. En este sentido la posibilidad de poder comprar bienes de más alto valor agregado, como automóviles o viviendas, supone un incentivo real a incrementar los ingresos personales y la productividad, cuya vinculación se ha declarado como un objetivo explícito en el actual proceso.

\subsection{Impulso de nuevas capacidades productivas}

Los lineamientos incluyen también entre sus prioridades la recapitalización de la economía, cuando se proponen garantizar el mantenimiento de una adecuada distribución de la riqueza entre el consumo inmediato y la acumulación (lin.40). Una recapitalización dirigida prioritariamente a la esfera productiva (lin.118), algo que parece necesario si se tiene en cuenta el retroceso sostenido en el peso del sector productivo en la estructura del producto cubano (pasando de representar, según datos de la ONE, un 41,6\% del PIB en 2003 a un $36,8 \%$ del PIB en $2009^{39}$ ) y el importante papel de este sector en la generación del excedente económico y en la sostenibilidad fiscal del propio crecimiento.

A pesar de la declaración explícita en el informe central del VI Congreso sobre la incompatibilidad con el sistema socialista de acumular y concentrar capital privadamente, los lineamientos abren nuevas posibilidades de expandir las capacidades productivas tanto en la esfera no estatal como en las microindustrias locales. Con ese objetivo se contempla otorgar créditos a trabajadores por cuenta propia, a campesinos, a cooperativas agropecuarias y

\footnotetext{
${ }^{39}$ Si bien es cierto que los cambios metodológicos introducidos en 2004 en la medición del PIB (que pasaba a valorar los servicios sociales en función de su precio de mercado y no de su coste) pudieron disminuir el peso del sector productivo para ese año, el hecho de que este sector haya reducido de forma sostenida su participación relativa en el producto con respecto a 2004, apunta a la existencia de otros factores, más allá de los aspectos puramente metodológicos. Se asume la definición de Sector productivo propuesta por la ONE, que incluye los sectores agropecuario, industria, minería y energía, turismo, construcción y transporte y comunicaciones.
} 
Palacios, Juan Carlos. La reforma de la economía cubana. Evaluación de su potencial impacto en el crecimiento económico.

a las proyectadas cooperativas industriales y de servicios. Complementariamente se establece la necesidad de que la industria metalmecánica aumente la producción de bienes de equipo con el objetivo de cubrir las potenciales demandas de bienes de equipo procedentes de dichos sectores (lin.217).

\subsection{Estabilización macroeconómica}

El documento aprobado incluye también medidas dirigidas a controlar los desequilibrios fiscales y exteriores, con el objetivo de garantizar la sostenibilidad del crecimiento en el largo plazo. En materia de control fiscal destacan: la eliminación de la financiación de las pérdidas empresariales (lin.18), la reducción de las unidades presupuestadas (lin.31 y 32), el ajuste de los gastos sociales a los recursos financieros del país (lin.64) y la eliminación ordenada de la libreta de abastecimiento y de gratuidades indebidas (lin.174).

Para el control del déficit de la Balanza de Pagos se plantea incrementar y diversificar las exportaciones (lin.76). Con ese objetivo se planean crear Zonas Especiales de Desarrollo (lin.103), buscar soluciones a los actuales obstáculos internos que impiden alcanzar mayores niveles de eficiencia en las empresas exportadoras (lin.91) y avanzar en los acuerdos de integración económica con América latina y el Caribe, priorizando la participación en el ALBA (lin.114 y 115). Se fija también como objetivo acelerar el proceso de sustitución de importaciones, prioritariamente en los sectores agropecuarios y de bienes de equipo (lin.87 y 88$)^{40}$.

Las transformaciones propuestas en el proyecto de lineamientos presentan interesantes posibilidades de incrementar tanto las capacidades productivas como los niveles de eficiencia global de la economía, lo que en buena lógica, debería incidir positivamente en las tasas de crecimiento del PIB cubano de los próximos años. El análisis del documento propuesto permite también identificar una serie de cuestiones que aún siendo compatibles con los límites propios de un modelo socialista, y presentando un notable potencial de incidir positivamente en la eficiencia y en el crecimiento, no han sido incluidos en el programa de cambios. Así como aspectos incluidos en el mismo, que pueden incidir negativamente en la solución de algunos de los principales problemas estructurales de la economía cubana. En especial, destacan los siguientes:

- Mantenimiento de precios subvencionados. El acceso al consumo de bienes básicos, podría garantizarse mediante políticas redistributivas que garantizaran un poder adquisitivo suficiente para su provisión, sin tener que introducir distorsiones en los precios de dichos productos que dificulten la medición de los hechos económicos ${ }^{41}$. El proyecto actual se propone sin

\footnotetext{
${ }^{40} \mathrm{Si}$ bien el hecho de que casi la mitad de las tierras cultivables del país estén ociosas (ONE, varios años) concede un amplio margen para avanzar en la sustitución de importaciones de productos agropecuarios. Para el caso de los bienes de equipo, parece sin embargo un objetivo más difícil de conseguir en el corto y medio plazo, considerando las escasas posibilidades del país para financiar el desarrollo de una industria pesada competitiva.

${ }^{41}$ Partiendo de la premisa de que el Estado no puede redistribuir sin coste alguno, Stiglitz (1998) argumenta que se debe optar por aquellas formas de intervención que afecten en menor grado al mecanismo de precios derivado de las leyes de la oferta y la demanda. El coste de fijar precios máximos sería elevado en este sentido, al crear escasez artificial al precio controlado.
} 
Palacios, Juan Carlos. La reforma de la economía cubana. Evaluación de su potencial impacto en el crecimiento económico.

embargo mantener el carácter centralizado de los precios de aquellos productos y servicios que económica y socialmente interese regular (lin.68), planteándose medidas dirigidas a propiciar la estabilidad de precios incluso, en aquellas ofertas no estatales vinculadas a necesidades básicas de la población (lin.71).

- Desarrollo limitado del trabajo por cuenta propia. El listado de profesiones autorizadas a ejercer el trabajo por cuenta propia deja fuera a un conjunto importante de profesionales (arquitectos, ingenieros, diseñadores gráficos, economistas, entre otros), lo que puede propiciar la pérdida de aquel capital humano que acabe dirigiéndose hacia trabajos no cualificados pero con mayores ingresos potenciales. El hecho de que algunos de los impuestos vinculados a esta modalidad laboral hayan aumentado, sugiere una concepción de la medida más dirigida a objetivos recaudatorios que a incrementar los niveles de eficiencia.

- Mantenimiento del tamaño de la Administración. Parece lógico que en una economía más descentralizada como la propuesta en el reciente Congreso, el tamaño de la Administración y de la burocracia presente cierto margen para su reducción, pues ésta debería jugar un papel menos importante en la toma de decisiones económicas. Dicha racionalización tendría un efecto positivo e inmediato en el equilibrio fiscal del país, sin embargo, y a diferencia de lo que ocurrió en el anterior proceso de descentralización de la economía en los 90, esta vez no se incluye la racionalización de la Administración como un objetivo explícito ${ }^{42}$.

- Fuentes de competitividad no explotadas. Las exportaciones de las Asociaciones Económicas Internacionales representan desde el 2002 más del $50 \%$ del total de exportaciones de mercancías en Cuba (Pérez, 2010b: 38). Considerando que las empresas mixtas asumen el coste laboral en pesos convertibles y que los trabajadores reciben como salario la misma cantidad en pesos cubanos, existe un importante margen para reducir el coste laboral para este tipo de empresas, lo que haría sus exportaciones mucho más competitivas en el mercado internacional y sería un estímulo importantísimo para atraer nuevas inversiones extranjeras con capacidad de exportar y de transferir tecnología al país, en un momento en que la imagen que los inversores extranjeros tienen de Cuba, puede haberse dañado con la reciente aplicación de medidas como las retenciones practicadas en las cuentas bancarias de estas empresas. La política salarial de las empresas mixtas sigue basándose por tanto en una visión cortoplacista de captación de divisas (lin.100).

- Posible pérdida de capacidades productivas: la posibilidad de liquidar aquellas empresas con pérdidas sostenidas es una de las medidas con un mayor potencial de mejorar la eficiencia de la economía, al permitir endurecer la restricción financiera de las empresas. Las características de la economía cubana, con importantes y generalizadas distorsiones en precios, costes, ratios financieras, hacen sin embargo muy difícil distinguir entre aquellas empresas que son verdaderamente rentables de las que no lo son. En esas circunstancias, la propuesta de liquidar las empresas con pérdidas sostenidas presenta el importante riesgo de perder capacidades

\footnotetext{
${ }^{42}$ El exceso de burocracia ha sido identificada históricamente como uno de los principales problemas asociados al socialismo real (un análisis más profundo sobre el papel de la burocracia en el socialismo y los principales problemas puede consultarse en Hegedus (1979)).
} 
Palacios, Juan Carlos. La reforma de la economía cubana. Evaluación de su potencial impacto en el crecimiento económico.

productivas realmente competitivas, si no se precede de un periodo inicial de homogeneización mínima de las condiciones empresariales ${ }^{43}$. Algo que parece no estar contemplado a priori en el proyecto de lineamientos.

- Incapacidad de canalizar el ahorro hacia la inversión productiva: la propiedad de los medios de producción sigue siendo una de las principales líneas rojas a la que parece seguir circunscribiéndose cualquier reforma del modelo cubano. Actualmente se da la paradoja de que una economía descapitalizada en algunos de sus sectores ${ }^{44}$ presenta un importante volumen de liquidez acumulada en manos de la población ${ }^{45}$. Si bien los cambios propuestos flexibilizan la compra de bienes de capital por parte de la esfera no estatal, ésta parece seguir concibiéndose de forma limitada y a pequeña escala. Estas limitaciones que parecen entendibles para la acumulación privada del capital dentro de un sistema socialista, se vuelven más incomprensibles cuando se trata de permitir el desarrollo, reproducción y expansión de formas de propiedad esencialmente socialistas, como las cooperativas, limitando el potencial productivo de éstas y su contribución a la mejora de la eficiencia global de la economía. El aprovechamiento de economías de escala seguiría restringiéndose de esa forma al ámbito estatal, impidiendo que las empresas no estatales reduzcan sus costes medios a largo plazo mediante la expansión de su capacidad productiva (Stiglitz, 2004: 194)

- Falta de estímulo a la competencia empresarial: en un ambiente microeconómico en el que existan incentivos para que las empresas mejoren sus resultados, el estímulo de la competencia supondría una importante palanca para que éstas aumentaran su productividad y redujeran sus costes. Cabe señalar que aunque los lineamientos prevén por vez primera el estímulo material a empresarios, bajo el actual marco regulatorio las empresas no tienen incentivos reales para mejorar sus resultados, más allá del estricto cumplimiento del plan. Es por eso, que las ganancias de eficiencia que la teoría económica vincula a una mayor competencia en precios (Stiglitz, 2004: 289) requerirán en el caso cubano de incentivos reales para que las empresas mejoren sus resultados. En ese sentido, la vigencia de la regla de fijación de precios basada en los costes actualmente utilizada en la mayoría de precios minoristas (lin.69), puede suponer una importante fuente de ineficiencia si no se crean las necesarias condiciones de competencia empresarial. Actualmente el precio se fija incrementando un por ciento sobre los costes, por lo que al no existir competencia las empresas tienden a inflar sus costes para de esa forma obtener mayores diferenciales. La mejora de la competitividad en el mercado interno, supondría a su vez un importante paso para poder competir en los mercados internacionales e incrementar así las exportaciones del país.

- Riesgo de reproducir la restricción financiera blanda a nivel ministerial o de organización empresarial superior: según establece el lineamiento número

\footnotetext{
${ }^{43}$ Muchas de las empresas que actualmente no son rentables no lo son porque se ven obligadas a vender a precios por debajo de sus costes o en una moneda diferente a la que compran algunos de sus insumos (Xalma, 2002).

${ }^{44}$ Las bajas tasas de inversión de las últimas dos décadas han sido insuficientes en sectores como el agropecuario o la industria ligera para cubrir la propia depreciación del stock de capital (calculado a partir de datos ONE).

${ }^{45} 20.200$ millones de pesos en 2006 (Banco Central de Cuba, varios años).
} 
Palacios, Juan Carlos. La reforma de la economía cubana. Evaluación de su potencial impacto en el crecimiento económico.

22, las empresas aportarán parte de sus utilidades después de impuestos para crear en la organización superior de dirección empresarial un fondo de compensación destinado a cubrir desbalances financieros. La exigencia con la que sean gestionados estos fondos, así como las condiciones en que una empresa pueda acogerse a ellos, serán cuestiones a tener muy en cuenta si no se quiere que la actual restricción financiera blanda se reproduzca ya no a nivel estatal, sino a nivel ministerial o de organización empresarial superior.

- Inexistencia de mecanismos que permitan la convertibilidad monetaria en el sistema empresarial: el marco regulatorio actual no permite a las empresas cubanas cambiar sus ingresos de una moneda a otra. Si bien la eliminación de la dualidad monetaria es un objetivo recogido en el programa de lineamientos, la ausencia hasta entonces de mecanismos de convertibilidad monetaria como los que existen en el sector de la población (CADECAS), reduce notablemente la autonomía de un sector empresarial, cuyo acceso a las divisas sigue dependiendo de decisiones gubernamentales. La creación de dos subsistemas empresariales (el tradicional, que opera en pesos cubanos y el emergente, que opera en CUC) supone además una importante discriminación empresarial y sectorial que afecta a la medición de variables económicas tan importantes como rentabilidad o competitividad y que explica en gran medida, los pobres resultados productivos de algunos sectores que operan mayoritariamente en pesos cubanos, como el agropecuario.

- Concepción ambigua y cortoplacista del proceso de reordenamiento laboral: el discurso oficial apunta a que no se renuncia al objetivo del pleno empleo sino al del pleno empleo en el sector estatal. Dado que el pleno empleo en el sector no estatal es una variable no controlable directamente por el gobierno sino que dependería del mercado, a través de la posibilidad de los diferentes agentes de alcanzar beneficios, se estaría aceptando tácitamente el desempleo. Ese hecho, supondría en sí mismo uno de los cambios más sustanciales derivados del actual proceso. Sin embargo, la forma en que éste ha sido concebido y explicado podría estar desaprovechando espacios abiertos en el nuevo escenario con un importante potencial de incrementar la productividad laboral. El primero podría encontrarse en la capacidad de vincular en el discurso oficial, el proceso de disponibilidad laboral con variables claves como la motivación o la disciplina en el trabajo. La desmotivación, la indisciplina laboral o la corrupción han sido identificadas en el pasado como uno de las principales lacras de la economía del país ${ }^{46}$, por lo que sorprende que una vez superado el principal tabú (aceptación del desempleo, aunque sea de forma tácita), no se haya aprovechado el nuevo escenario para vincular las mencionadas variables al mantenimiento del puesto de trabajo en aquellas actividades con subempleo declarado. Existe una segunda laguna relativa al carácter coyuntural o estructural del proceso abierto. Hasta este momento, la población desconoce si la posibilidad de ser declarado disponible es una medida extraordinaria circunscrita a la actual coyuntura o si por el contrario, supone el inicio de una nueva concepción de las relaciones laborales en la economía cubana. Un

\footnotetext{
${ }^{46}$ Han sido numerosas las campañas impulsadas sin éxito por el gobierno para luchar contra el hurto y desvío de recursos de las empresas estatales hacia el mercado negro (a modo de ejemplo se puede consultar http://cubaalamano.net/sitio/client/article.php?id=7065).
} 
Palacios, Juan Carlos. La reforma de la economía cubana. Evaluación de su potencial impacto en el crecimiento económico.

escenario, este último, con mayores posibilidades de incrementar la productividad, lo que podría retroalimentarse en un círculo virtuoso formado por motivación, productividad y salario real.

\section{Conclusiones}

La correlación existente entre los indicadores de eficiencia (PTF o productividad del capital) y los índices de descentralización económica presentados en este trabajo, suponen un primer indicio sobre la posibilidad de que un marco regulatorio favorable a la centralización económica esté limitando la expansión del producto del país. Adicionalmente, en el análisis del crecimiento económico cubano puede identificarse una alta sensibilidad del PIB a la evolución de sus exportaciones, contrastada en la totalidad de los trabajos empíricos que han estimado Modelos de Crecimiento Restringidos por la Balanza de Pagos para la economía cubana.

La historia de la economía caribeña durante las últimas décadas sugiere que la alternancia de etapas de centralización y descentralización económica, ha dependido en gran medida del grado de afectación de la restricción externa al funcionamiento de la economía. En ese sentido, se observa que los dos shocks externos sufridos en esta etapa (desaparición de la URSS y crisis económica internacional) han requerido de una actuación inmediata sobre la restricción interna de la economía, (estimulando los niveles de eficiencia con reformas en el marco regulatorio) con el objetivo de evitar el colapso del sistema. Una constatación que supone un primer indicio de la posible interrelación entre las restricciones de oferta y demanda y que justifica seguir profundizando en el futuro en esa línea de investigación, por su relevancia en la comprensión del crecimiento económico cubano y de sus principales determinantes.

En este sentido, las reformas incluidas en el VI congreso presentan un importante potencial para propiciar mejoras en la eficiencia, por el avance que suponen en materia de autonomía empresarial, de mejora del ambiente microeconómico y de incentivos, lo que a su vez debe coadyuvar a la expansión de las capacidades productivas y a la mejora del equilibrio de la Balanza de Pagos.

Sin embargo, algunas medidas con un importante potencial para incrementar la productividad de la economía, como los estímulos a la competencia, la convertibilidad monetaria en el sector empresarial o una mejor canalización del ahorro a la inversión productiva, no han sido incluidas en la actual agenda de cambios, a pesar de su aparente compatibilidad con el modelo de producción socialista.

Igualmente, es importante señalar la existencia de otros riesgos potenciales para el crecimiento de la economía cubana en los próximos años. Entre los más importantes se encuentra el volumen de recursos que el gobierno cubano tendrá que destinar en el corto plazo al pago de una deuda externa acelerada 
Palacios, Juan Carlos. La reforma de la economía cubana. Evaluación de su potencial impacto en el crecimiento económico.

en esta última etapa ${ }^{47}$. Esta circunstancia afectará negativamente a la disponibilidad de recursos de la economía y al crecimiento económico del país, por lo que tendrá que ser considerada en el análisis futuro del impacto del VI congreso del PCC en los resultados productivos del modelo socialista cubano.

47 Según Estimaciones de la Economist Intelligence Unit en 2011 superó el 22\% del PIB cubano. 
Palacios, Juan Carlos. La reforma de la economía cubana. Evaluación de su potencial impacto en el crecimiento económico.

\section{REFERENCIAS BIBLIOGRÁFICAS}

Álvarez, E. (1995): "Impacto de la Inversión Extranjera en la sociedad cubana", Cuba: investigación económica. Vol. 4, 1-15.

Arrow, K. (1962): "The Economic Implications of Learning By Doing", Reviews of Economics Studies, No. 29, 155-172.

Banco Central de Cuba (varios años): Boletín Anual. La Habana, Cuba.

Barro, R. J. (1990): "Government Spending in a Simple Model of Endogenous Growth", Journal of Political Economy, Vol. 98, No. 5, 26-103

Betancourt, A. P. (2007): "Entrevista concedida al diario Granma el 23 de enero de 2007". Disponible en:

http://www.cubaminrex.cu/mirar_cuba/Economia/entrevistas_entrevista\%20 a\%20armando\%20perez\%20betancourt_tc.htm

Cabarrouy, E. A. (1999): "La importancia de la pequeña empresa no estatal en el mejoramiento de la capacidad productiva de la economía cubana", informe de la décima reunión de la Association for the Study of the Cuban Economy (ASCE)". Miami. Disponible en http://cicia.uprrp.edu/forum/Vol.\%207.1/1.pdf

Castañeda, H. (1982): "Criterios e indicadores de eficiencia económica (I y II)", Economía y Desarrollo, Vol. 69 y 70, 1-15.

Chuairey, A. (2008): "La sustitución de importaciones en Cuba: un enfoque de elasticidades". Tesis de Maestría. Universidad de la Habana.

Comisión Económica Para América Latina y Caribe (varios años): Anuarios Estadísticos de América Latina y el Caribe. Santiago de Chile, Chile.

Leal, E. (2011): "Solos sería imposible", en Cuba Debate, 2 de Enero de 2011, disponible en: http://www.cubadebate.cu/opinion/2011/01/02/eusebio-lealsolos-seria-imposible/

Cribeiro, Y. y Triana, L. (2005): "Las elasticidades en el comercio exterior cubano. Dinámica de corto y largo plazo". Tesis de grado, Universidad de La Habana.

Deere, C. D. (1995): "Cuba: Adapting to a Post-Soviet World", The New Agrarian Reforms NACLA Report on the Americas, Vol. 29 (2), 13-17.

Doimeadios, Y (2007): "El crecimiento económico en Cuba: un análisis desde la Productividad Total de los Factores". Editorial Universitaria de la Universidad de la Habana.

Economist Inteligence Unit (varios años): Country Report Cuba. Emily Morris, Londres, Reino Unido. Disponible en www.eiu.com.

El mundo (2008): "Cuba valora en 5.000 millones de dólares los daños provocados por Ike y Gustav", 16/09/2008. Disponible en:

http://www.elmundo.es/elmundo/2008/09/16/internacional/1221529580.html

Figueroa, V. A. y Castellón, C. (1983): "La eficiencia de la producción en la economía socialista", Revista Economía y Desarrollo No.72. 18-29.

Figueras, M. A. (1999): Aspectos estructurales de la economía cubana. Félix Varela, La Habana.

Fugarolas, G. y Matesanz, D. (2005): "Restricción de balanza de pagos y vulnerabilidad externa en la Argentina de los noventa. Un análisis de caso", MPRA, Paper 210, University Library of Munich, Alemania.

Fugarolas, A.U. , Matesans, D. y Mañalich, I (2009): "Empirical evidence of the balance of payment constrained growth in Cuba. The effects of commercial regimes since 1960", Versus Academica, Vol. 3, 58-67. 
Palacios, Juan Carlos. La reforma de la economía cubana. Evaluación de su potencial impacto en el crecimiento económico.

García, A. (1998): "Impacto económico del turismo en Cuba", Cuba: investigación económica, Vol. 4, 31-45.

González, A., Martínez, R., Oñate, N. y Hidalgo, V. (1989): “Utilización de las funciones de producción macroeconómicas para el análisis de la eficiencia factorial", INIE folleto.

Griliches, Z. (1958): "Research Costs and Social Returns: Hybrid Corn and Related Innovations", Journal of Political Economy, Vol. 66 (5), 419-431.

Griliches, Z. (1979): "Issues in assessing the contributions of R\&D to productivity growth", Bell Journal of Economics, Vol. 10, 92-116.

Hegedus, A. (1979): Socialismo y burocracia. Peninsula, Barcelona.

Kornai, J. (1979): "La reproducción de la escasez", Econométrica Vol. 47, 801819.

Lavigne, M. (1995): Del socialismo al Mercado. La difícil transición económica de la Europa del Este. Oikos nomos, Ediciones Encuentros.

Loría, E. (2001): "La restricción externa dinámica al crecimiento de México, a través de las propensiones del comercio, 1970-1999", Estudios Económicos, vol. 16, № 2, 17-36, México, D.F., El colegio de México.

Lucas, R. (1982): "Interest Rates and Currency Prices in a Two-Country World", Journal of Monetary Economics, Vol. 10 (3), 335-59.

Madrid, M. (1997): "Growth and technological change in Cuba", Cuba in Transition. Vol. 7, 216-228.

Marquetti, H. (2006): "La reestructuración del sistema empresarial en Cuba: tendencias principales", Reflexiones sobre Economía Cubana, 297-343.

Mendoza, Y. y Álvarez, P. (2002): "El crecimiento económico y la inversión en Cuba", Cuba: Investigación Económica, Vol. 4, 1-42.

Mendoza, Y. (2003): “ ¿Ha sido importante el capital humano en el crecimiento económico de Cuba?", Publicaciones INIE, versión enero 2004, La Habana, Cuba.

Mendoza Y. y Robert, L (2000): "El Crecimiento Económico y las Restricciones en el Sector Externo: Una Aplicación al Caso Cubano", Cuba: Investigación Económica, Vol. 3, 1-22.

Mesa-Lago, C. (1993): "The economic effect on Cuba of the downfall of socialism in the USSR and Eastern Europe", Cuba after the Cold War, Pittsburgh, University of Pittsburgh Press, 37-59.

Mesa-Lago, C. (2003): "La economía cubana al comienzo del siglo XXI: evaluación del desempeño y perspectivas". Boletín Elcano, 16. Disponible en: http://www.realinstitutoelcano.org/wps/portal/rielcano/contenido?WCM GLOBAL_CONTEXT=/elcano/elcano_es/zonas_es/mediterraneo+y+mundo +arabe/dt7-2003.

Moreno-Brid, J.C. (1998): "On Capital Flows and the Balance of payments constrained growth model", Journal of Post Keynesian Economics, Vol. 21, 283-298.

Nova, A. (1998): "Las nuevas relaciones de producción en la agricultura", Cuba: investigación económica, Vol. 1, 1-13.

Nova, A. (2010): "La cadena productiva y comercializadora en el sector agropecuario cubano", Caminos. Revista Cubana de pensamiento socioteológico, Vol. 55-56, 22-32. 
Palacios, Juan Carlos. La reforma de la economía cubana. Evaluación de su potencial impacto en el crecimiento económico.

Oliveira J. y F. García (2004): "Productivity of Nations: a stochastic frontier approach to TFP decomposition". Escola de Economia de Sao Paulo, textos para discussao, 143, diciembre 2004. Disponible en:

http://bibliotecadigital.fgv.br/dspace/bitstream/handle/10438/1945/TD143.pdf ?sequence $=1$

Oficina Nacional de Estadísticas (varios años). Anuarios Estadísticos. La Habana.

Palacios, J. C. (2010): "Decentralization and productivity: the Cuban case". Capítulo del libro "Institute of Economics - UBRAS", en sección de los Urales de la Academia de Ciencias de Rusia. Editores: A. Tartarkin y A. Sánchez-Andrés. Julio del 2010, Ekaterinburg, 109-121.

Pérez, V. et al (2003): "los trabajadores por cuenta propia en Cuba", Cuba Siglo $X X I, \mathrm{n}^{\circ}$ 47. Disponible en:

http://www.nodo50.org/cubasigloXXI/economia2.htm

Pérez, O. E. (2006): "La inversión extranjera directa en el desarrollo económico. La experiencia cubana", Reflexiones Sobre Economía Cubana, 61-92, Instituto Cubano del Libro, La Habana, Cuba.

Pérez, O. E. (2010): "Estrategia económica: medio siglo de socialismo", 1-24. 50 años de la Economía Cubana. Editorial de Ciencias Sociales, La Habana.

Pérez, O. E. (2010b): "La inversión Extranjera en China, Vietnam y Cuba: experiencias necesarias", Seminario Anual sobre Economía Cubana y Gerencia Empresarial, 24-25 Junio 2010, La Habana.

Quiñones, N. Mañalich, I. y Pico, N. (2010): "El sector externo cubano y sus retos estructurales". Mimeo.

Rodríguez, G. (1985): El proceso de industrialización de la economía cubana. Editorial Ciencias Sociales, La Habana, Cuba.

Rodríguez, J. L. (1990): Estrategia del desarrollo económico en Cuba. Editorial de Ciencias Sociales, La Habana, Cuba.

Schultz, T. (1961): "Investment in human capital", American Economic Review, vol. 51, 1-17.

Solow, R. (1957): "Technical Change and the Aggregate Production Function", The Review of Economics and Statistics, Agosto, 312-320.

Stiglitz, J. E. (2004): Principios de Microeconomía. Ariel, Barcelona (1 ${ }^{a}$ ed. 1998).

Thirlwall, A. (1979): "The Balance of Payments Constraint as an Explanation of International Growth Rate Differences", Banca Nazionale del Lavoro Quarterly Review, 1-128.

Torres, R. (2007): "Cambio estructural y crecimiento económico en Cuba: un enfoque a partir del uso de los factores productivos", Boletín Trimestral del Centro de Estudios de la Economía Cubana, 28-45.

Cribeiro, Y. y Triana, L. (2005): "Las elasticidades del comercio exterior cubano: dinámica de corto y largo plazo". Tesis de Diploma, Facultad de Economía, Universidad de La Habana.

Vidal P. y Fundora, A. (2008): "Relación Comercio -crecimiento en Cuba: estimaciones con el filtro de Kalman", Revista CEPAL Vol. 94, abril, 101120.

Xalma, C. (2002): "La dolarización cubana como instrumento de intervención económica. Eficacia y sostenibilidad de una alternativa". Tesis Doctoral, Universidad de Barcelona. 